\title{
Conditional Müller Cell Ablation Causes Independent Neuronal and Vascular Pathologies in a Novel Transgenic Model
}

\author{
Weiyong Shen, ${ }^{1}$ Marcus Fruttiger, ${ }^{2}$ Ling Zhu, ${ }^{1}$ Sook H. Chung, ${ }^{1}$ Nigel L. Barnett, ${ }^{3,4}$ Joshua K. Kirk, ${ }^{1}$ SoRa Lee, ${ }^{1}$ \\ Nathan J. Coorey, ${ }^{1}$ Murray Killingsworth, ${ }^{5}$ Larry S. Sherman, ${ }^{6}$ and Mark C. Gillies ${ }^{1}$ \\ ${ }^{1}$ Save Sight Institute, The University of Sydney, Sydney 2000, Australia; ${ }^{2}$ UCL Institute of Ophthalmology, University College London, London EC1V 9EL, \\ United Kingdom; ${ }^{3}$ Queensland Eye Institute, South Brisbane, 4101 Queensland, Australia; ${ }^{4}$ Centre for Clinical Research, The University of Queensland, \\ Brisbane, 4072 Queensland, Australia; ${ }^{5}$ South Western Sydney Clinical School, The University of New South Wales, Sydney, NSW 2052 Australia; ${ }^{6}$ Division \\ of Neuroscience, Oregon National Primate Research Center, Oregon Health and Science University, Beaverton, Oregon 97006
}

Müller cells are the major glia of the retina that serve numerous functions essential to retinal homeostasis, yet the contribution of Müller glial dysfunction to retinal diseases remains largely unknown. We have developed a transgenic model using a portion of the regulatory region of the retinaldehyde binding protein 1 gene for conditional Müller cell ablation and the consequences of primary Müller cell dysfunction have been studied in adult mice. We found that selective ablation of Müller cells led to photoreceptor apoptosis, vascular telangiectasis, blood-retinal barrier breakdown and, later, intraretinal neovascularization. These changes were accompanied by impaired retinal function and an imbalance between vascular endothelial growth factor-A (VEGF-A) and pigment epithelium-derived factor. Intravitreal injection of ciliary neurotrophic factor inhibited photoreceptor injury but had no effect on the vasculopathy. Conversely, inhibition of VEGF-A activity attenuated vascular leak but did not protect photoreceptors. Our findings show that Müller glial deficiency may be an important upstream cause of retinal neuronal and vascular pathologies in retinal diseases. Combined neuroprotective and anti-angiogenic therapies may be required to treat Müller cell deficiency in retinal diseases and in other parts of the CNS associated with glial dysfunction.

\section{Introduction}

Müller cells are specialized glia that serve numerous functions essential to retinal homeostasis. Playing a central role in retinal glucose metabolism, they are intimately connected to photoreceptors and other neurons, which they protect through the uptake and degradation of glutamate through the glutamate aspartate transporter, as well as by release of neurotrophic factors and secretion of the antioxidant, glutathione (Bringmann et al., 2006). Müller cells are also involved in the formation and maintenance of the inner blood-retinal barrier (BRB), which consists

Received June 12, 2012; revised Aug. 20, 2012; accepted Aug. 30, 2012.

Author contributions:W.S., M.F., and M.C.G. designed research;W.S., L.Z., S.H.C., N.L.B., J.K.K., S.-R.L., N.J.C., and M.K. performed research; M.F. contributed unpublished reagents/analytic tools; W.S., L.Z., S.H.C., N.L.B., J.K.K., and N.J.C. analyzed data; W.S., L.S.S., and M.C.G. wrote the paper.

This study was supported by grants from Lowy Medical Research Institute, National Health and Medical Research Council (APP1028393), Ophthalmic Research Institute of Australia, Rebecca L. Cooper Medical Research Foundation, and University of Sydney Bridging Grant. Mark Gillies is a fellow of Sydney Medical School Foundation and supported by a National Health and Medical Research Council (Australia) Practitioner Fellowship. L.S.S. was supported by National Institutes of Health Grant P51 RR000163. We are grateful to Elizabeth Williams, Tracy Doan, Linda Wernbacher, and Elizabeth $0^{\prime}$ Brien for their assistance in production of Rlbp1-CreER transgenic mice. We also thank Mario R. Capecchi for providing the Rosa-DTA176 transgenic line, Diego Guidolin for the customized-image analysis software, An Nguyen for assistance in animal work, and Paul Martin for his critical appraisal of this manuscript.

The authors declare no competing financial interests.

Correspondence should be addressed to Weiyong Shen, Save Sight Institute, the University of Sydney, 8 Macquarie Street, Sydney 2000, Australia. E-mail: weiyong.shen@sydney.edu.au.

DOI:10.1523/JNEUROSCI.2841-12.2012

Copyright $\odot 2012$ the authors $\quad 0270-6474 / 12 / 3215715-13 \$ 15.00 / 0$ of tight junctions between endothelial cells and also depends on the surrounding glia to maintain a precisely regulated microenvironment for neuronal activity (Erickson et al., 2007). Müller cells likely provide an antiproliferative condition in the healthy retina by releasing anti-angiogenic factors such as pigment epithelium-derived factor (PEDF) and thrombospondin-1 (Bringmann et al., 2006; Abukawa et al., 2009). Thus Müller cell dysfunction may result in an imbalance between anti-angiogenic and pro-angiogenic factors, leading to BRB breakdown and angiogenesis (Bringmann et al., 2009; Ali et al., 2011).

Müller cells are a potential key player in retinal diseases such as diabetic retinopathy (DR) and macular telangiectasia type 2 (MacTel-2) (Barber et al., 2000; Fletcher et al., 2007; Powner et al., 2010; Sallo et al., 2011). Diabetes induces Müller cell abnormalities including increased expression of glial fibrillary acidic protein (GFAP), reduction of glutamine synthetase (GS), and decreased activity of the glutamate transporter (Bringmann et al., 2006). Müller glial alterations have been reported to precede overt retinal neuronal and vascular pathologies in DR (Barber et al., 2000; Fletcher et al., 2007). MacTel-2 was initially distinguished clinically by vascular changes including right-angled venules, vascular telangiectasis, and leak as well as deep retinal neovascularization arising from the retinal vasculature (Gass and Blodi, 1993; Yannuzzi et al., 2006). Recent studies, however, indicate that loss of vision in MacTel-2 is a result of photoreceptor degeneration or loss (Charbel Issa et al., 2010; Ooto et al., 2011). 
Histological analysis of an eye from a MacTel-2 patient revealed prominent loss of Müller cell markers in the central retina (Powner et al., 2010).

Most previous studies on the interrelationships between Müller glial dysfunction and retinal pathologies have relied on animal models in which Müller glial dysfunction was a secondary effect of retinal injury. The precise link between Müller cell dysfunction and retinal pathology, however, remains unclear. To examine the consequences of primary Müller glial deficiency in the retina, we generated an inducible transgenic model using a portion of the regulatory region of the retinaldehyde binding protein 1 (Rlbp1) gene as a cell-specific promoter along with a Cre/Lox-P approach for Müller cell-specific gene targeting. The resultant Rlbp1CreER transgenic mice were crossed into Rosa-DTA176 mice, a transgenic line carrying an attenuated form of the diphtheria toxin fragment A (DTA176) gene, for conditional Müller cell ablation. Our findings demonstrate that Müller glia dysfunction may have a so far unappreciated role and may provide a mechanistic link between neuronal damage and vascular pathology in retinal diseases.

\section{Materials and Methods}

Transgene construction for generating Rlbp1-CreER transgenic mice. Experiments were approved by the University of Sydney Animal Ethics and Biosafety Committees. A $3 \mathrm{~kb}$ fragment of the Rlbp1 gene, previously shown to drive Müller cell-specific gene expression (Vázquez-Chona et al., 2009), was amplified from C57BL6 genomic DNA using Phusion high-fidelity DNA polymerase (New England BioLabs). The forward primer (CATGGAGGAGTTAATTAAACGCGTAAGGTGGGCTGCTTGG) contained the restriction enzyme sites Pacl and Mlu1 for subsequent cloning and a sequence in $677 \mathrm{bp}$ upstream of the exon 1 of the Rlbp1 gene. The reverse primer (CACTGAGTCGACCATGGTTTCTGCAAGTTGTGACTTCTGTAGACACCAAGA) contained a Sall restriction enzyme site, a Kozak-ATG sequence (see Fig. $1 A$ ) and a sequence in exon 2 of the Rlbpl gene. The PCR product was agarose gel purified and cloned into a previously described plasmid (ref PMID: 19850870) using the Pacl and Sall restriction sites. A linear $7 \mathrm{~kb}$ transgene fragment (Fig. $1 A$ ) from this plasmid was used to produce Rlbp1-CreER transgenic mice by pronuclear injection into single-cell C57BL/6J $\times$ CBA embryos, which were then transplanted into pseudopregnant females.

Genotyping Rlbp1-CreER transgenic mice. Transgenic animals were screened by PCR unique to the mouse Rlbp1 gene. The set of primers 1 and 2 were as follows: primer 1-forward CCTCACAGCGGTCA CTTTTGGTAG and reverse GGAGGGCAGGCAGGTTTTGGTG, primer 2-forward CACAGCGGTCACTTTTGGTAGATA and reverse GCGCAGCAGGGTGTTGTAGG. Using these two sets of primers, 624 and 1100 bp PCR products were detected specifically in Rlbp1-CreER transgenic mice only.

Crossing Rlbp1-CreER mice into Rosa-LacZ and Rosa-DTA176 transgenic lines. Rlbp1-CreER transgenic mice were crossed into Rosa-LacZ reporter mice (The Jackson Laboratory; Stock\# 003474) for tamoxifen (TMX)-induced LacZ expression and into Rosa-DTA176 mice for conditional Müller cell ablation. To analyze the Cre-induced LacZ or DTA176 gene expression, offspring received daily intraperitoneal injection of TMX ( $3 \mathrm{mg}$ per dose, dissolved in sunflower oil) at 6-8 weeks of age for 2 or multiple days. To localize LacZ gene expression, Rlbp1CreER-lacZ mice were killed $4 \mathrm{~d}$ after the last TMX injection, their eyes fixed in $0.25 \%$ glutaraldehyde for $1 \mathrm{~h}$. Cryosections were produced for 5 -bromo-4-chloro-3-indolyl- $\beta$-D-galactopyranoside) staining to detect $\beta$-galactosidase ( $\beta$-gal) activity.

Cryosection and flat-mount immunohistochemistry. Eyes were briefly fixed in $4 \%$ paraformaldehyde (PFA) for $5 \mathrm{~min}$ and then anterior segments were removed. After postfixation in $4 \%$ PFA for $1 \mathrm{~h}$, eye cups were either transferred to PBS containing 30\% sucrose and then embedded in optimal cutting temperature compound for cryosection immunohistochemistry (IHC), or placed in PBS for retinal flat-mount IHC. For cryosection IHC, frozen sections were blocked with $5 \%$ normal goat serum and incubated with an antibody to GS (1:100; Millipore Bioscience Research Reagents), cleaved-caspase 3 (1:100; Cell Signaling Technology), SOX9 (1:200; Millipore Bioscience Research Reagents), GFAP (1:250; Dako), collagen IV (1:250; AbD serotec), smooth muscle actin (SMA; 1:20; Dako), CD31 (1:50; BD), or vascular endothelial growth factor-A (VEGF-A; 1:50, Santa Cruz Biotechnology). Bound antibodies were detected with Alexa Fluor 488- or 594-conjugated goat or donkey secondary antibodies (1:1000; Invitrogen).

For flat-mount staining, dissected eye cups were fixed in $4 \%$ PFA for $1 \mathrm{~h}$ and then placed in PBS at $+4^{\circ} \mathrm{C}$ overnight. On the next day, retinas were isolated, rinsed in PBS, and permeabilized with $1 \%$ Triton X-100 containing 5\% normal goat serum blocking solution for at least $2 \mathrm{~h}$. Retinas were incubated in $100 \mu \mathrm{l}$ of solution containing fluorescenceconjugated peanut agglutinin (PNA, $10 \mu \mathrm{g} / \mathrm{ml}$; Invitrogen) to label cone photoreceptor outer segments (POS) or Griffonia simplicifolia isolectin B4 (IB4; $10 \mu \mathrm{g} / \mathrm{ml}$; Sigma) for retinal vessels in $0.1 \mathrm{M}$ PBS with $1 \%$ bovine serum albumin (BSA) and $0.5 \%$ Triton X-100 overnight at $+4^{\circ} \mathrm{C}$. PNAlabeled images were processed and quantitatively analyzed using computer-based image analysis software with customized macroroutines as described previously (Guidolin et al., 2004; Shen et al., 2006).

To directly correlate retinal vascular abnormalities with photoreceptor injury, retinas were incubated with a mixture consisting of Alexa Fluor 594-conjugated IB4 (10 $\mu \mathrm{g} / \mathrm{ml}$; Invitrogen $)$ and fluorescence-conjugated PNA $(10 \mu \mathrm{g} / \mathrm{ml}$; Invitrogen). To correlate retinal vascular changes with alterations of tight junction protein claudin- 5 expression, retinas were incubated with a mixture consisting of Alexa Fluor 488-conjugated IB4 (10 $\mu \mathrm{g} / \mathrm{ml}$; Invitrogen) and a rabbit polyclonal antibody to claudin-5 (1:100; Zymed). The bound antibody was detected with Alexa Fluor 594-conjugated secondary antibody (1:1000; Invitrogen). Retinas were flattened onto Superfrost-plus microscope slides and mounted for confocal laser scanning microscopy.

Terminal deoxynucleotidyl transferase dUTP nick end labeling. Frozen sections were examined for apoptotic cells with Roche in situ cell death detection kit (Catalog No. 11684795910; Roche Applied Science) according to instructions and followed by propidium iodide nuclear counterstaining (10 $\mu \mathrm{g} / \mathrm{ml}$; Invitrogen) for confocal laser scanning microscopy.

Light and electron microscopy. For light microscopy, eye cups were fixed in $4 \%$ PFA for $2 \mathrm{~h}$ and embedded in paraffin. Hematoxylin and eosin staining was performed on $5 \mu \mathrm{m}$ paraffin sections. For electron microscopy, eye cups were fixed in 2\% PFA plus $2.5 \%$ glutaraldehyde in $0.1 \mathrm{M}$ cacodylate buffer for $24 \mathrm{~h}$ followed by rinsing in $0.1 \mathrm{M} \mathrm{Na}$ cacodylate buffer for $2 \mathrm{~h}$. The eye cups were then postfixed in $1 \% \mathrm{OsO}_{4}$ in $0.1 \mathrm{M}$ cacodylate buffer for $2 \mathrm{~h}$, followed by another $1 \mathrm{~h}$ wash and dehydration with graded ethanol solutions. Samples were incubated overnight in a 1:2 mixture of propylene oxide and Epon/Araldite (Sigma-Aldrich) and then placed in $100 \%$ resin followed by embedding. The blocks were sectioned for high-magnification electron microscopy.

Electroretinography. Full-field electroretinography (ERG) was performed to assess retinal function as previously described (Moxon-Lester et al., 2009). Briefly, mice were dark adapted overnight, anesthetized by intraperitoneal injection of a mixture of xylazine $(15 \mathrm{mg} / \mathrm{kg})$, ketamine $(75 \mathrm{mg} / \mathrm{kg})$, and acepromazine $(2 \mathrm{mg} / \mathrm{kg}$ ) and the pupils dilated with $1 \%$ tropicamide and $2.5 \%$ phenylephrine. A single- or twin-flash paradigm was used to elicit mixed (rod and cone) or isolated cone responses, respectively. Flash stimuli for mixed responses were provided by a photographic flash unit (Mecablitz 60CT4; Metz), over a stimulus intensity range of -4.2 to $3.0 \mathrm{log}$ cd.s.m ${ }^{-2}$. Interstimulus interval was increased from $2 \mathrm{~s}$ for the lowest intensities to $5 \mathrm{~min}$ for the highest intensities to allow complete recovery of the b-wave between stimuli. Isolated cone responses were obtained over the same intensity range following a rodsaturating stimulus of $2.1 \mathrm{log} \mathrm{cd} . \mathrm{s} . \mathrm{m}^{-2}$ given $400 \mathrm{~ms}$ before the test stimulus. This short interval after a rod-saturating flash does not allow recovery of rod function, thereby revealing cone-only responses. Isolated rod responses were obtained by digital subtraction of the cone response from the mixed response at each stimulus intensity. The a-wave amplitude was measured from the baseline to the trough of the a-wave response and the b-wave amplitude was measured from the trough of the $a$-wave to the peak of the b-wave. Data were expressed as the mean wave amplitude \pm SEM $(\mu \mathrm{V})$. Two-factor repeated measures ANOVA was 
A

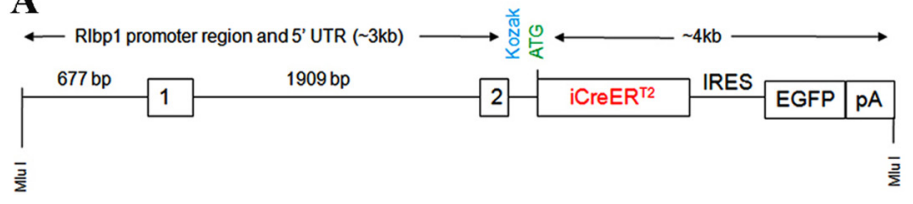

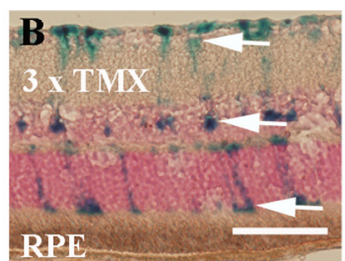

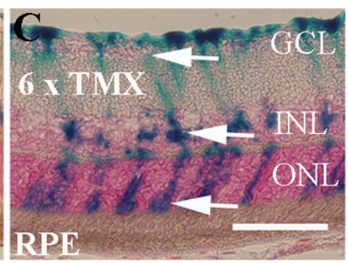

H

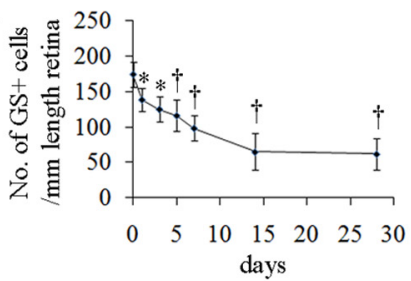

M

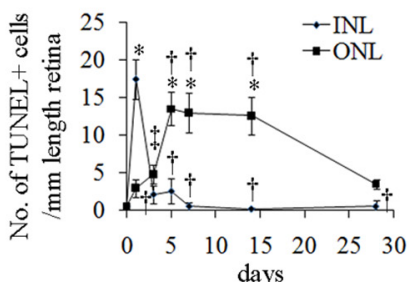

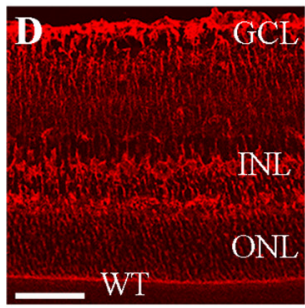
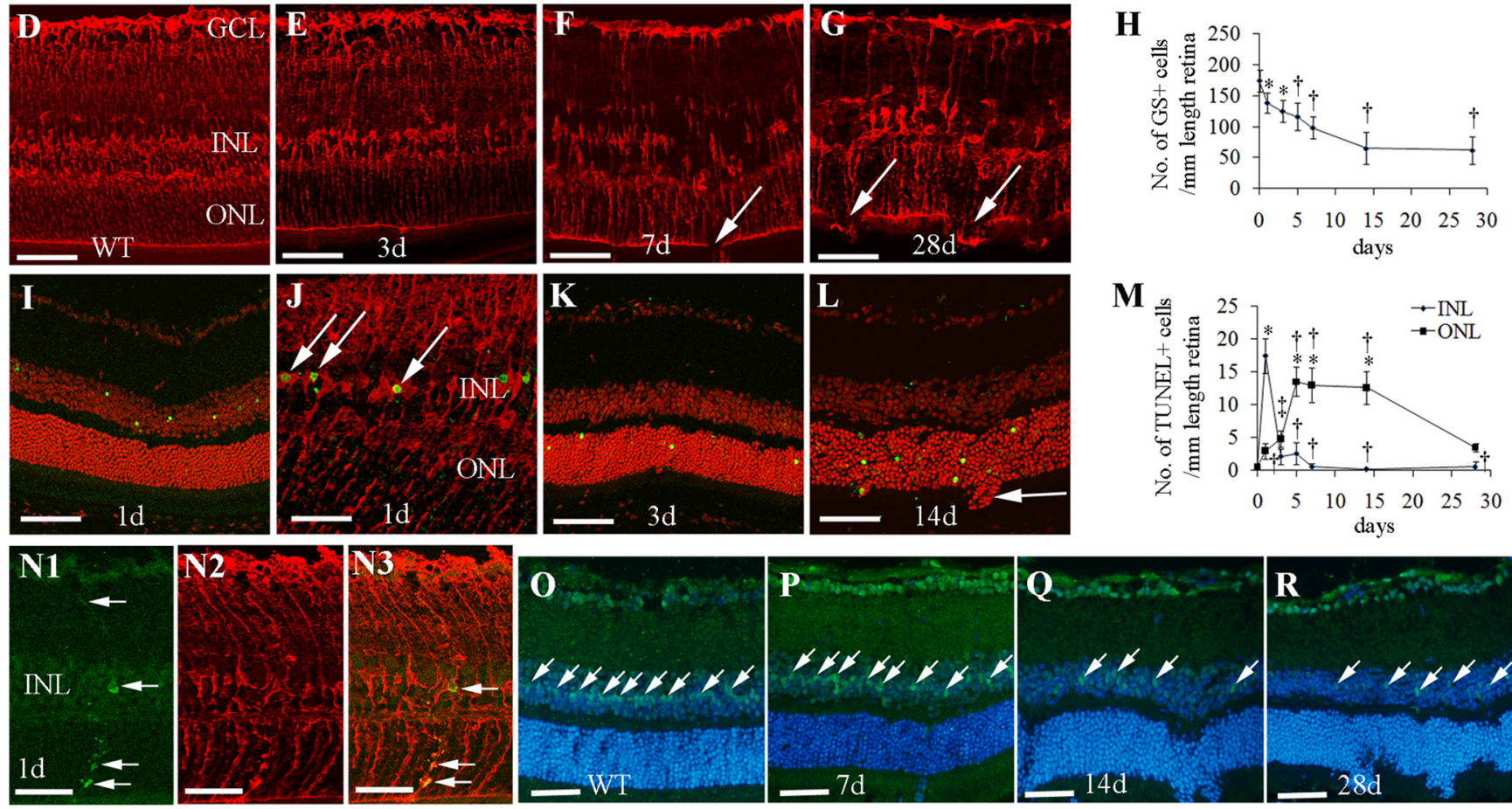

Figure 1. Generation of transgenic (TG) mice for conditional Müller cell ablation. $A$, Schematic presentation of the $7 \mathrm{~kb}$ Mlul fragment used to generate Rlbp1-CreER TG mice. $B, C$, LacZ expression in Müller cells (arrows) $4 \mathrm{~d}$ after various doses of TMX induction in Rlbp1-CreER-LacZ mice. D-G, Immunostaining for GS in wild-type (WT; D) and RIbp1-CreER-DTA176 mice (E-G) after four consecutive doses of TMX treatment. Arrows $(\boldsymbol{F}, \boldsymbol{G})$ point to regions with the broken 0LM due to loss of Müller cells. $\boldsymbol{H}$, Quantitative analysis of Müller cell loss over time. ${ }^{*} p<0.05,{ }^{\dagger} p<0.01 ;$ both versus day 0 , respectively; $n=8-10$ per time point. $I, K, L$, TUNEL staining (green) showed that apoptotic cells were confined to the INL $1 \mathrm{~d}$ after TMX treatment $(\boldsymbol{I})$, followed later by a wave of cell death in the ONL $(\boldsymbol{K}, \boldsymbol{L})$. Sections were counterstained with propidium iodide. J, Double labeling for GS (red) and TUNEL (green) confirmed that apoptotic cells (arrows) in the INL were Müller cells $1 \mathrm{~d}$ after TMX treatment. $M$, Quantitative analysis of TUNEL-positive cells in the INL and ONL between 1 and $28 \mathrm{~d}$ after TMX treatment. ${ }^{*} p<0.01,{ }^{\ddagger} p<0.05$, both versus day 0 ; ${ }^{\dagger} p<0.01$, versus $1 \mathrm{~d}$; $n=6-8$ in each group. $\mathbf{N 1 - N 3}$, Colocalization of a cleaved-caspase $3^{+}$cell with a GS ${ }^{+}$Müller cell in the INL $1 \mathrm{~d}$ after TMX induction. The cleaved-caspase ${ }^{+}$cell possesses the typical morphology of Müller glia (arrows in $\mathbf{N} \mathbf{1}$ and $\mathbf{N 3}$ ). $\mathbf{0}-\boldsymbol{R}$, immunostaining using SOX9 as a Müller nuclear marker (green, arrows) and Hoechst nuclear counterstaining (blue) showing that Müller cell loss in the INL was well correlated with photoreceptor damage in the ONL. GCL, ganglion cell layer; RPE, retinal pigment epithelium. Scale bars: $\boldsymbol{B}-\mathbf{G}, \mathbf{I}, \boldsymbol{K}-\boldsymbol{L}, \boldsymbol{N}-\boldsymbol{R}, 50 \mu \mathrm{m} ; \boldsymbol{J}, 25 \mu \mathrm{m}$.

performed to compare the responses from transgenic and wild-type mice over the flash stimulus range. The amplitudes of the inner retinal-derived oscillatory potentials (OPs), which are superimposed on the rising phase of the b-wave, were calculated as described by Bui et al. (2002).

Fundus fluorescein angiography. Fundus fluorescein angiography (FA) were performed using a modified clinical fundus camera (Topcon TRC$50 \mathrm{VT}$ ) mounted with a $40 \mathrm{D}$ lens as previously described (Shen et al., 2010).

Intravitreal injection of ciliary neurotrophic factor (CNTF) and VEGFB20-4.1.1. Intravitreal injection of ciliary neurotrophic factor (CNTF; Sigma, \#C3710) and VEGFB20-4.1.1 (Genentech) was performed using a 32-gauge needle attached to a Hamilton syringe. One microliter solution was injected intravitreally and the contralateral eye received balanced salt solution (BSS) containing the same concentration of BSA as a control in each mouse.

Quantitative measurement of retinal vascular permeability. BRB breakdown was quantitatively evaluated by measuring retinal vascular permeability to fluorescein isothiocyanate (FITC)-conjugated dextran as described previously with slight modifications (Miyahara et al., 2004; Shen et al., 2010). In brief, after deep anesthesia, FITC-dextran (MW = $70 \mathrm{kDa}, 25 \mathrm{mg} / \mathrm{kg}$; Sigma) was injected intravenously. Fifteen to twenty minutes after injection, the chest cavity was opened and a perfusion cannula was introduced into the aorta. A blood sample was collected immediately before perfusion. After achieving drainage from the right atrium, each mouse was perfused with saline $(500 \mathrm{ml} / \mathrm{kg})$ to clear the remaining intravascular dextran. The blood sample was centrifuged at $7000 \mathrm{rpm}$ for $20 \mathrm{~min}$ at $4^{\circ} \mathrm{C}$, and the supernatant was diluted at 1:1000. After perfusion, the retinas were carefully removed, weighed, and homogenized to extract the FITC-dextran in $0.25 \mathrm{ml}$ of water. The extract was processed for fluorescence reading using a spectrofluorometer with excitation $485 \mathrm{~nm}$ and emission $538 \mathrm{~nm}$. Corrections were made by subtracting the reading of water blank. For normalization, the amount of FITC-dextran within the retina was divided by the retinal weight and by the concentration of FITC-dextran in the plasma. BRB breakdown was calculated using an equation described previously (Miyahara et al., 2004; Shen et al., 2010), with the results being expressed in microliters per gram per hour.

Western blot. For Western blot, proteins were be extracted from retinas and their concentrations determined by DC protein assay. Equal amounts of proteins were subjected to SDS-PAGE, transferred to a polyvinylidene difluoride membrane for Western blot. Membranes were probed with antibodies to GFAP (mouse monoclonal, 1:5000; Neomarker), VEGF (mouse monoclonal, 1:5000; Abcam), and PEDF (goat polyclonal, 1:200; R\&D Systems). After incubation with secondary antibodies conjugated with horseradish peroxidase, protein bands were visualized using the G:Box BioImaging systems and quantified using the 

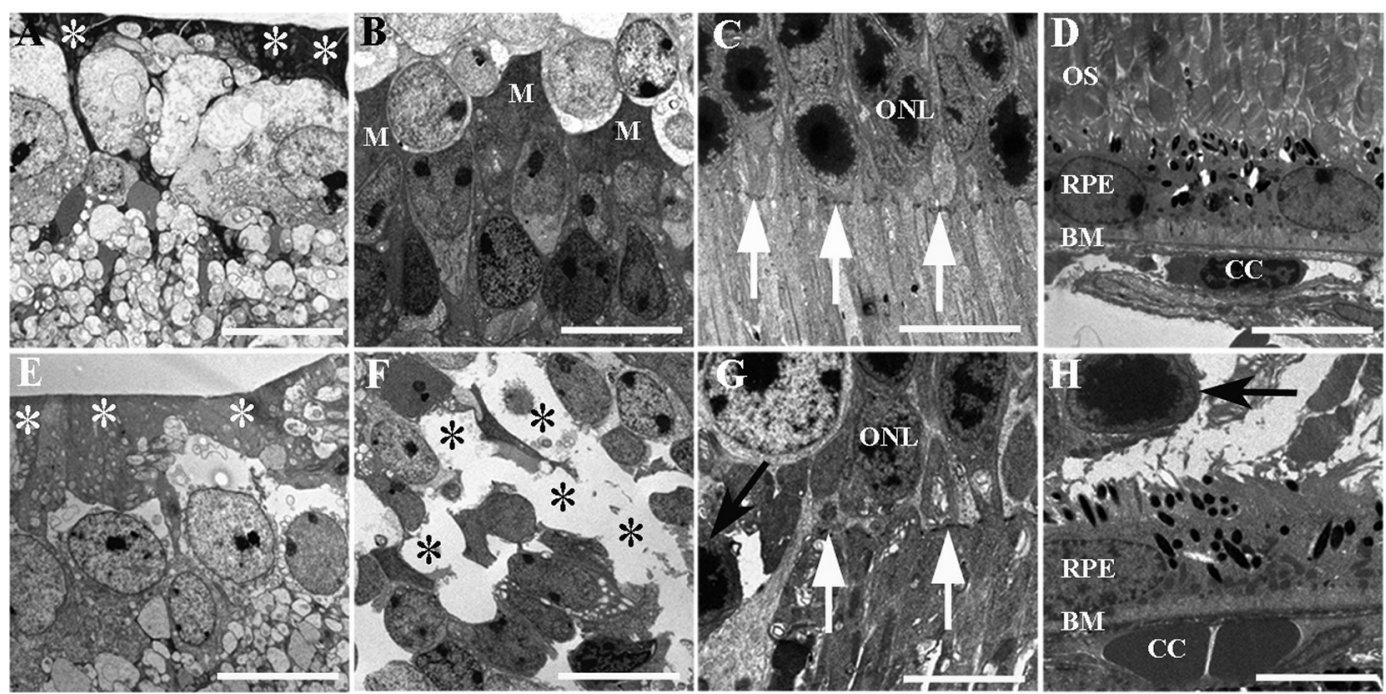

Figure 2. Changes in retinal ultrastructure after conditional Müller cell ablation. $A-H$, Electron micrographs showing ultrastructural changes $14 \mathrm{~d}$ after TMX treatment. $A-D$, Wild-type retina. $\boldsymbol{E}-\boldsymbol{H}$, Müller cell ablation induced by TMX in transgenic mice resulted in reduced electron-dense end feet of the Müller glia in the ILM (white asterisks in $\boldsymbol{E}$ ), loss of Müller somata in the INL (black asterisks in $\boldsymbol{F}$ ), absence of the $0 \mathrm{LM}$ (white arrows in $\boldsymbol{G}$ ), and protrusion of photoreceptor nuclei (black arrows in $\boldsymbol{G}$ and $\boldsymbol{H}$ ) into the subretinal space, but the RPE remained relatively normal $(\boldsymbol{H}$ ). $\mathrm{M}$, Müller cells; $0 \mathrm{NL}=$ outer nuclear layer, 0 S, photoreceptor outer segments; BM, Bruch membrane; CC, choroidal capillaries. Scale bars: $10 \mu \mathrm{m}$.

A

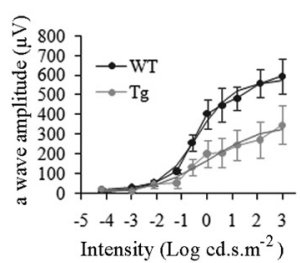

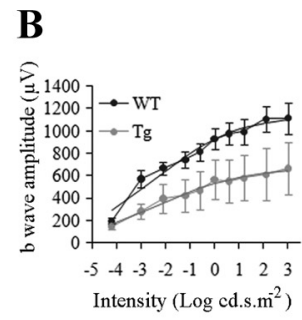
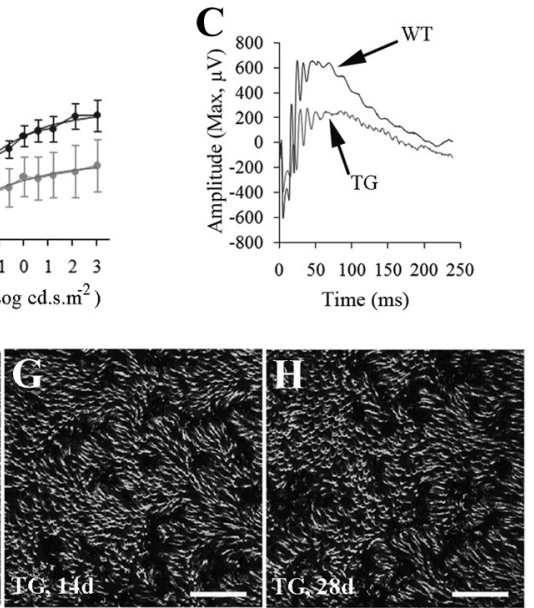

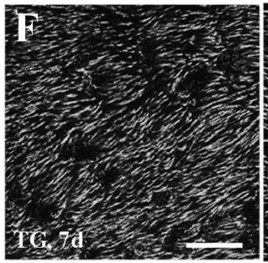

D
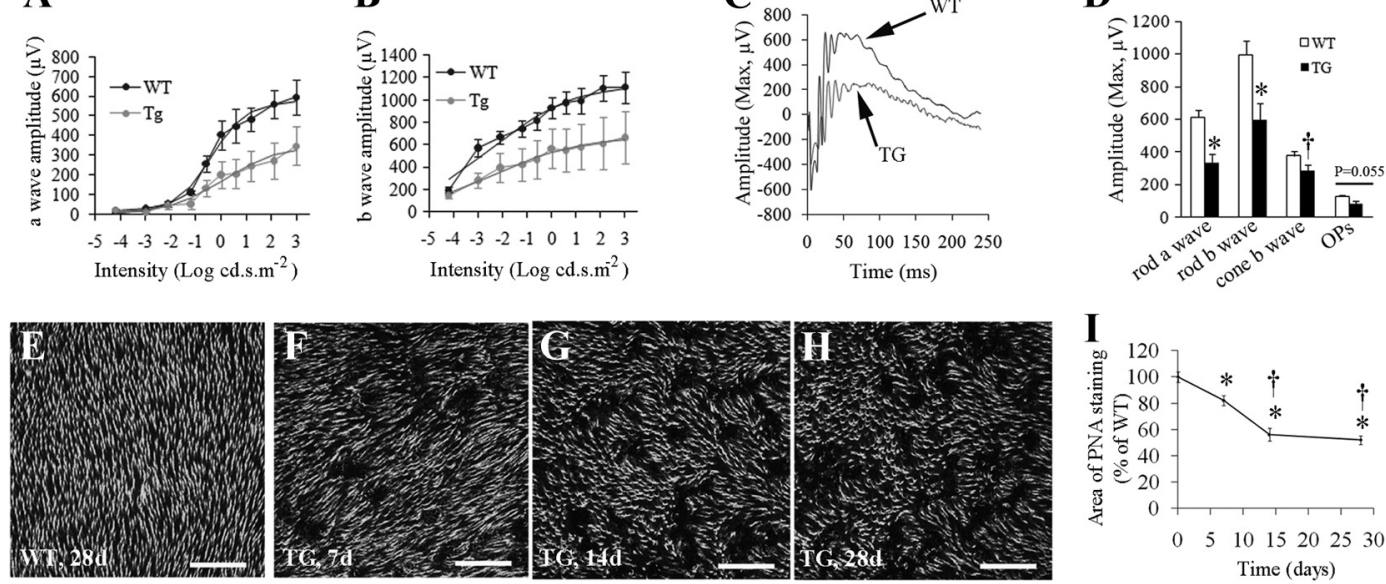

Figure 3. Impaired retinal function and photoreceptor damage after Müller cell ablation. $\boldsymbol{A}, \boldsymbol{B}$, Müller cell ablation resulted in abnormal ERG responses in transgenic (TG) mice, characterized by reduced amplitudes of both a-wave $(\boldsymbol{A})$ and $b$-wave $(\boldsymbol{B})$ responses. ERG was measured at flash intensities ranging from -4.2 to $+3.0 \log \mathrm{cd}$.s.m ${ }^{-2}$. C, Representative ERG showing maximum responses measured in wild-type (WT) and TG mice. D, Rod and cone responses to a twin-flash paradigm and changes in maximum OPs. The ERG was examined at 6 weeks after four consecutive doses of TMX treatment. ${ }^{*} p<0.01 ;{ }^{\dagger} p<0.05$, TG versus WT, $n=8$ in each group. $\boldsymbol{E}-\boldsymbol{H}$, Retinal whole-mount staining with PNA for cone POS. $\boldsymbol{I}$, Quantitative analysis of cone POS using customized image analysis software $(37,38) .{ }^{*} p<0.01$ versus day $0 ;{ }^{\dagger} p<0.01$ versus $7 \mathrm{~d} ; n=6-8$ in each group. Scale bars: $\boldsymbol{E}-\boldsymbol{H}, 100 \mu \mathrm{m}$.

GeneTools image scanning and analysis package. Protein expression was normalized to $\alpha / \beta$-tubulin (rabbit polyclonal, 1:2000; Cell Signaling Technology), which serves as a loading control.

Statistics. Results are expressed as mean \pm SEM. Data were analyzed using ANOVA for multiple comparisons (GB-STAT v9.0; Dynamic Microsystems) or paired $t$ test with a $p$ value $<0.05$ accepted as statistically significant.

\section{Results}

Generation of transgenic mice for conditional Müller cell ablation

We used a Cre/Lox-P approach to produce inducible transgenic mice for Müller cell-specific gene targeting. This construct contained a $2.6 \mathrm{~kb}$ portion of the regulatory region of the Rlbp 1 gene, which consists of the putative Rlbp1 promoter, the first two exons and the first intron of the Rlbp1 gene (Fig. 1A) that drives robust Müller cell-specific gene expression (Vázquez-Chona et al.,
2009). After crossing Rlbp1-CreER mice into Rosa-LacZ reporter mice (Maxwell et al., 1987; Wu et al., 2006), TMX given at 6 weeks of age induced LacZ expression in cells with the morphology of Müller glia showing radial processes extending from the inner limiting membrane (ILM) to the outer limiting membrane (OLM) and cell bodies in the inner nuclear layer (INL) (Fig. $1 B, C)$. LacZ expression was more extensive after higher doses of TMX (Fig. $1 B, C$ ). No LacZ expression was detected in the retinal pigment epithelium (RPE) or any other retinal cells (Fig. 1B,C). LacZ expression was not found in the brain (data not shown).

After crossing Rlbp1-CreER mice into Rosa-DTA176 mice, selective Müller cell ablation was observed as early as $1 \mathrm{~d}$ and became stable $14 \mathrm{~d}$ after TMX treatment in adult mice (Fig. $1 D-$ $H$ ). This was revealed by IHC for GS, which showed patchy loss of Müller cells in Rlbp1-CreER-DTA176 transgenic mice (Fig. 1 E$G)$. Müller cell loss and subsequent retinopathy were only ob- 

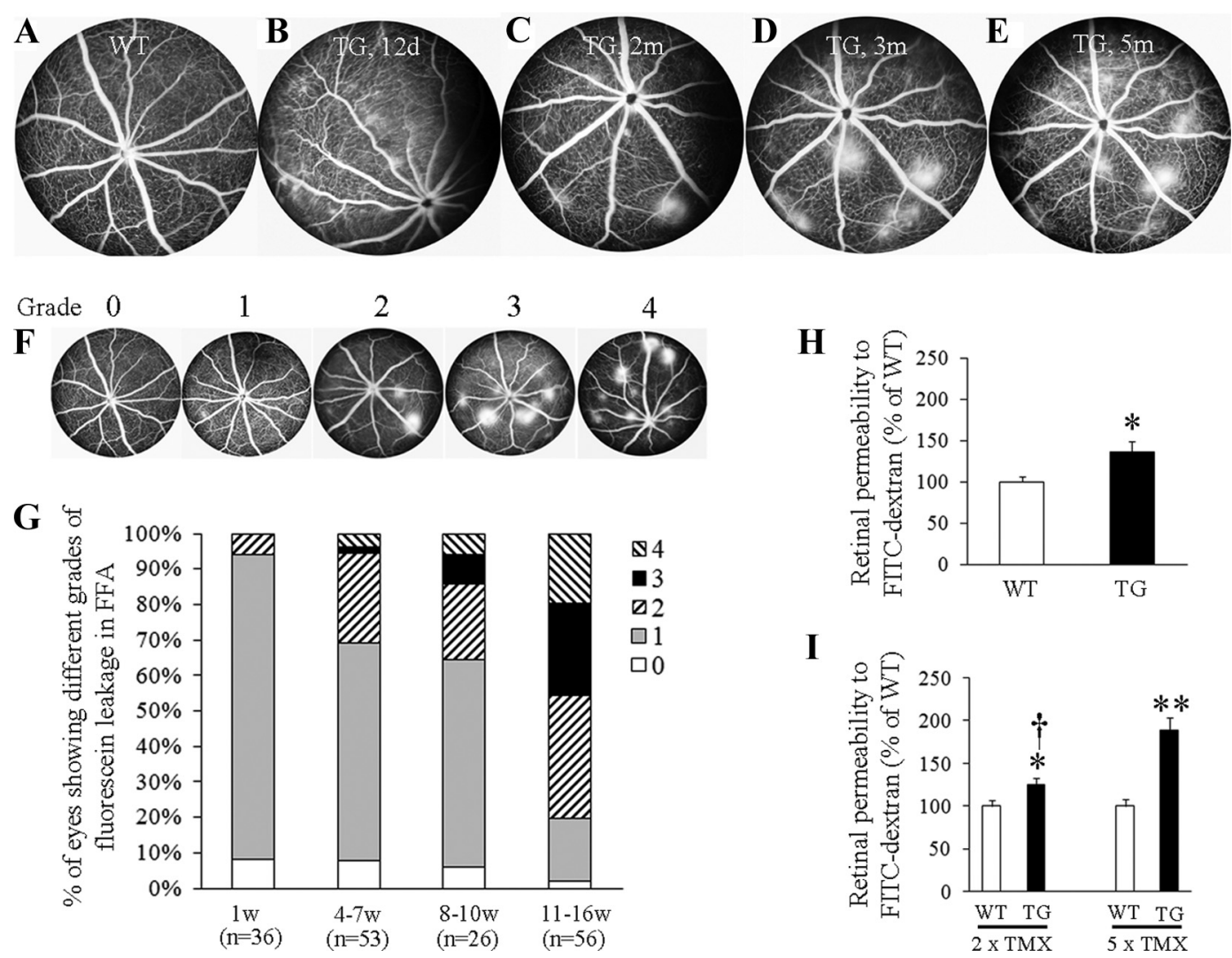

Figure 4. Müller cell ablation induces BRB breakdown. $\boldsymbol{A}$, Normal retinal vasculature in wild-type (WT) mice 3 months after TMX treatment. $\boldsymbol{B}$, Diffuse vascular leakage in transgenic (TG) mice $12 \mathrm{~d}$ after TMX treatment. $\boldsymbol{C}-\boldsymbol{E}$, Intense focal vascular leakage appeared from 2 months and persisted for at least 5 months after TMX treatment in TG mice. $\boldsymbol{F}$, Scales used for grading vascular leakage revealed by FA: "0," normal pattern of fluorescein filling with no vascular leakage; "1," readily identifiable lesions showing diffuse leakage but without intense focal vascular leakage; "2," intense focal vascular leakage appears but the lesion number $\leq 3$; "3," 4 - 6 lesions with intense focal vascular leakage; and " 4 ," $>6$ lesions with intense focal vascular leakage. G, Graded vascular leakage in TG mice from 1 to 16 weeks after TMX-induced Müller cell ablation. $\boldsymbol{H}$, Quantitative measurement of retinal vascular permeability to fluorescence-labeled dextran $12 \mathrm{~d}$ after five consecutive doses of TMX treatment. ${ }^{*} p<0.05, \mathrm{TG}, n=12$; WT controls, $n=18$.I, Retinal vascular permeability 5 months after various doses of TMX treatment. ${ }^{*} p<0.05 ;{ }^{* *} p<0.01$, TG versus WT controls; ${ }^{\dagger} p<$ $0.01,2 \times \mathrm{TMX}$ versus $5 \times \mathrm{TMX} ; n=10-12$ in each group.

served in TMX-treated Rlbp1-CreER-DTA176 transgenic mice but not in controls including (1) wild-type mice crossed with Rosa-DTA176 mice and treated with TMX, (2) R1bp1-CreERLacZ mice treated with TMX, (3) R1bp1-CreER-DTA176 mice treated with vehicle only (sunflower oil), and (4) R1bp1-CreERDTA176 mice without TMX treatment (data not shown).

Cell apoptosis, detected by terminal deoxynucleotidyl transferase dUTP nick end labeling (TUNEL) staining, occurred predominantly in the INL $1 \mathrm{~d}$ after TMX treatment in transgenic mice (Fig. $1 I, J, M$ ). Double-label staining using GS and TUNEL staining showed colocalization of Müller cell bodies and apoptotic cells in the INL (Fig. $1 \mathrm{~J}$ ). The Müller cell-specific killing $1 \mathrm{~d}$ after TMX induction was further confirmed by double-label IHC using cleaved-caspase 3 as an early marker of cell apoptosis in combination with the Müller cell-specific marker of GS (Fig. 1N1-N3). Following Müller cell death in the INL, a wave of cell apoptosis was observed in the outer nuclear layer (ONL) but not the other retinal layers (Fig. $1 M$ ). After gradually appearing from day 3 , the number of apoptotic cells in the ONL peaked between $5 \mathrm{~d}$ and $14 \mathrm{~d}$ then decreased $28 \mathrm{~d}$ after TMX treatment (Fig. $1 K-M)$. Furthermore, we used SOX9 as a nuclear marker to evaluate the relationship between Müller cell loss and photoreceptor injury. Our data showed that the areas of loss of Müller cell bodies in the INL were closely associated with photoreceptor injury in the ONL (Fig. 1O-R). As mouse cells do not have receptors for DTA, leak of DTA176 from dead Müller cells is unlikely to result in bystander effects on other retinal cells (Maxwell et al., 1987; Wu et al., 2006). To further exclude the bystander effect of extracellular DTA176, we extracted proteins from transgenic retinas $1 \mathrm{~d}$ and $7 \mathrm{~d}$ after TMX treatment. Intravitreal injection of retinal homogenates $(2 \mathrm{mg} / \mathrm{ml}$ protein concentration) in wildtype mice did not induce damage to the retinal structure, nor was cell apoptosis detected when examined $7 \mathrm{~d}$ after injection (data not shown).

Ultrastructural studies of wild-type mice treated with TMX showed a dense ILM with regular distribution of Müller cell bodies in the INL, an intact OLM and well organized POS (Fig. $2 A-C)$. Two weeks after TMX treatment, transgenic mice developed loss of the electron-dense end feet of Müller cells in the ILM, loss of Müller cell bodies in the INL, disruption of the OLM, protrusion of photoreceptor cell bodies into the subretinal space, and disorganized POS in areas of Müller cell ablation (Fig. 2E-G). RPE cells appeared unaffected in areas with photoreceptor damage in transgenic retinas compared with wild-type controls (Fig. 2D, $H$ ).

\section{Photoreceptor damage and impaired retinal function after} conditional Müller cell ablation

We used flash ERG to assess the functional consequences of Müller cell ablation. Six weeks following TMX treatment, transgenic mice showed significant reduction in the a-wave response at flash intensities greater than $-0.6 \log$ cd.s.m ${ }^{-2}$ and of the b-wave 

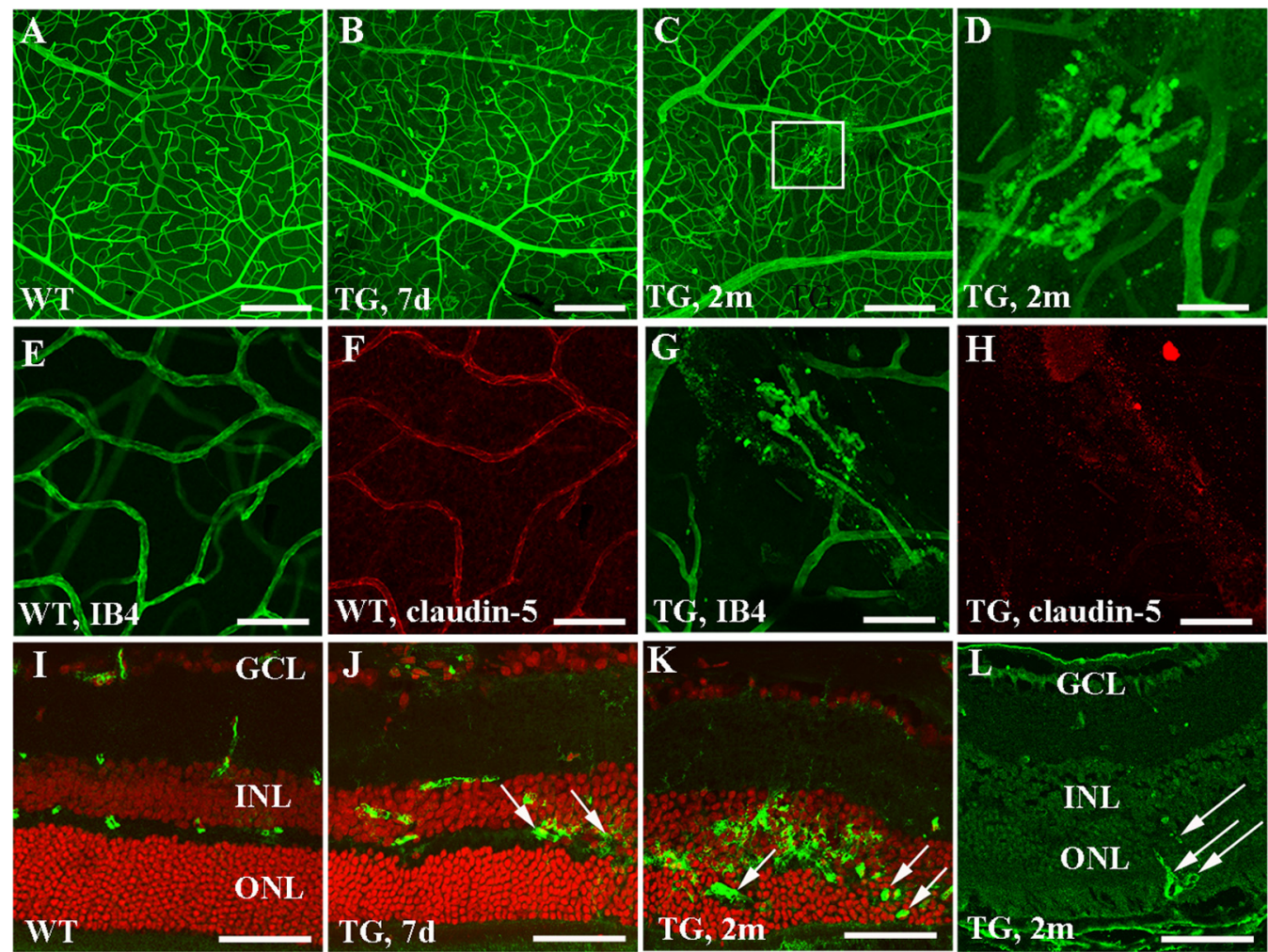

Figure 5. Müller cell ablation results in vascular telangiectasis and deep retinal neovascularization. $\boldsymbol{A}-\boldsymbol{D}$, Retinal flat-mount staining with IB4 showing increased vascular tortuosity $7 \mathrm{~d}(\boldsymbol{B})$ and intraretinal vascular tufts 2 months ( $\boldsymbol{C}$ and $\boldsymbol{D} ; \boldsymbol{D}$ is a higher power image of the squared area in $\boldsymbol{C}$ ) after TMX treatment in transgenic (TG) mice. $\boldsymbol{E}-\boldsymbol{H}$, Double labeling for IB4 (green, $\boldsymbol{E}$ and $\boldsymbol{G}$ ) and claudin-5 (red, $\boldsymbol{F}$ and $\boldsymbol{H}$ ) showing reduction of claudin-5 in the region of vascular tufts. $\boldsymbol{I}-\boldsymbol{L}$, Immunostaining for mouse lg $\mathrm{G}$ showing that vascular leakage was predominantly localized to deep retinal vessels in TG mice. $\boldsymbol{K}, \boldsymbol{L}$, Immunostaining for mouse lgG $(\boldsymbol{K})$ and collagen IV ( $\boldsymbol{L}$ ) showing growth of abnormal vessels (arrows) in the outer retina 2 months after Müller cell ablation. $G C L$, ganglion cell layer; INL, inner nuclear layer; ONL, outer nuclear layer. Scale bars: $\mathbf{A}-\mathbf{C}, 200 \mu \mathrm{m} ; \boldsymbol{E}-\boldsymbol{H}, 100 \mu \mathrm{m} ; \boldsymbol{D}, \mathbf{J}-\mathbf{L}, 50 \mu \mathrm{m}$.

response at flash intensities greater than $-3.0 \log \mathrm{cd} . \mathrm{s} . \mathrm{m}^{-2}$ (Fig. $3 A, B)$. With the maximum stimulation intensity $(3.0 \mathrm{log}$ cd.s. $\mathrm{m}^{-2}$ ), the amplitudes of both a- and b-waves in transgenic mice were significantly reduced to 52.8 and $58.7 \%$ of the values in wild-type controls, respectively (Fig. $3 A-C$ ). Maximum OP amplitudes in transgenic mice were reduced to $62 \%$ of wild-type control values, but this difference did not reach statistical significance (Fig. 3D, $p=0.055$ ). Using a twin-flash paradigm and digital subtraction, we isolated the cone-derived waveform from the rod response and found that both rod- and cone-derived b-waves were affected by Müller cell ablation (Fig. 3D).

Since results from studies on cell apoptosis, retinal ultrastructure, and ERG suggested that Müller cell ablation affects photoreceptors, we further examined photoreceptor damage using retinal flat mounts after PNA staining. Wild-type mice treated with TMX showed even labeling of cone POS (Fig. 3E). Patchy loss of cone POS was found in transgenic retinas, which proceeded for $14 \mathrm{~d}$ and became relatively stable $28 \mathrm{~d}$ after Müller cell ablation induced by TMX (Fig. $3 F-I$ ), which was consistent with the dynamics of Müller cell loss revealed by IHC (Fig. $1 E-H, P-R)$.

\section{Selective Müller cell ablation led to BRB breakdown}

We next tested whether Müller cell ablation caused BRB breakdown. Diffuse fluorescein leakage was commonly observed during fluorescein angiography between 1 and 2 weeks after TMX treatment, with areas of intense focal vascular leak developing after 2 months and then persisting for at least 5 months in transgenic mice (Fig. 4A-E). Semiquantitative analysis revealed that $31 \%$ of eyes developed lesions with intense focal vascular leakage (graded with a score of " 2 " or over; Fig. $4 F, G$ ) between 4 and 7 weeks and $36 \%$ between 8 and 10 weeks increasing to $80 \%$ at 11 and 16 weeks after TMX-induced Müller cell ablation (Fig. 4G). Quantitative analysis of BRB breakdown showed that the retinal vascular permeability to fluorescein-labeled dextran was significantly increased $12 \mathrm{~d}$ after TMX treatment in transgenic mice compared with wild-type controls (Fig. $4 H$ ). By 5 months after TMX treatment, a dose-dependent response to the numbers of TMX injections was found, with retinal vascular permeability increased to $125 \%(p<0.05)$ after two doses of TMX and $189 \%$ $(p<0.01)$ after five doses in transgenic mice compared with wild-type controls (Fig. 4I).

\section{Development of intraretinal vascular abnormalities and deep} retinal neovascularization

Retinal flat-mount staining using IB4 showed smooth and well defined retinal vessels in wild-type mice (Fig. $5 A$ ) while transgenic animals developed vascular telangiectasis as early as $7 \mathrm{~d}$ (Fig. 5B) and vascular tufts were frequently observed from 2 months after TMX treatment (Fig. 5C,D). IHC revealed a marked reduction in claudin-5 immunoreactivity on microvessels that were developing vascular tufts in transgenic mice (Fig. $5 E-H$ ). To identify the location of vascular leakage after Müller cell ablation, we performed immunostaining for mouse IgG. In wild-type retina, the immunoreactivity for mouse IgG was sharply restricted to vessels within the inner retina (Fig. 5I). Diffuse IgG immunoreactivity was observed around deep retinal vessels as early as $7 \mathrm{~d}$ after TMX treatment (Fig. 5J, arrows) and became more intense at 2 months when abnormal vessels had appeared in the deep retina (Fig. $5 K$, arrows) in transgenic mice. The growth of deep 


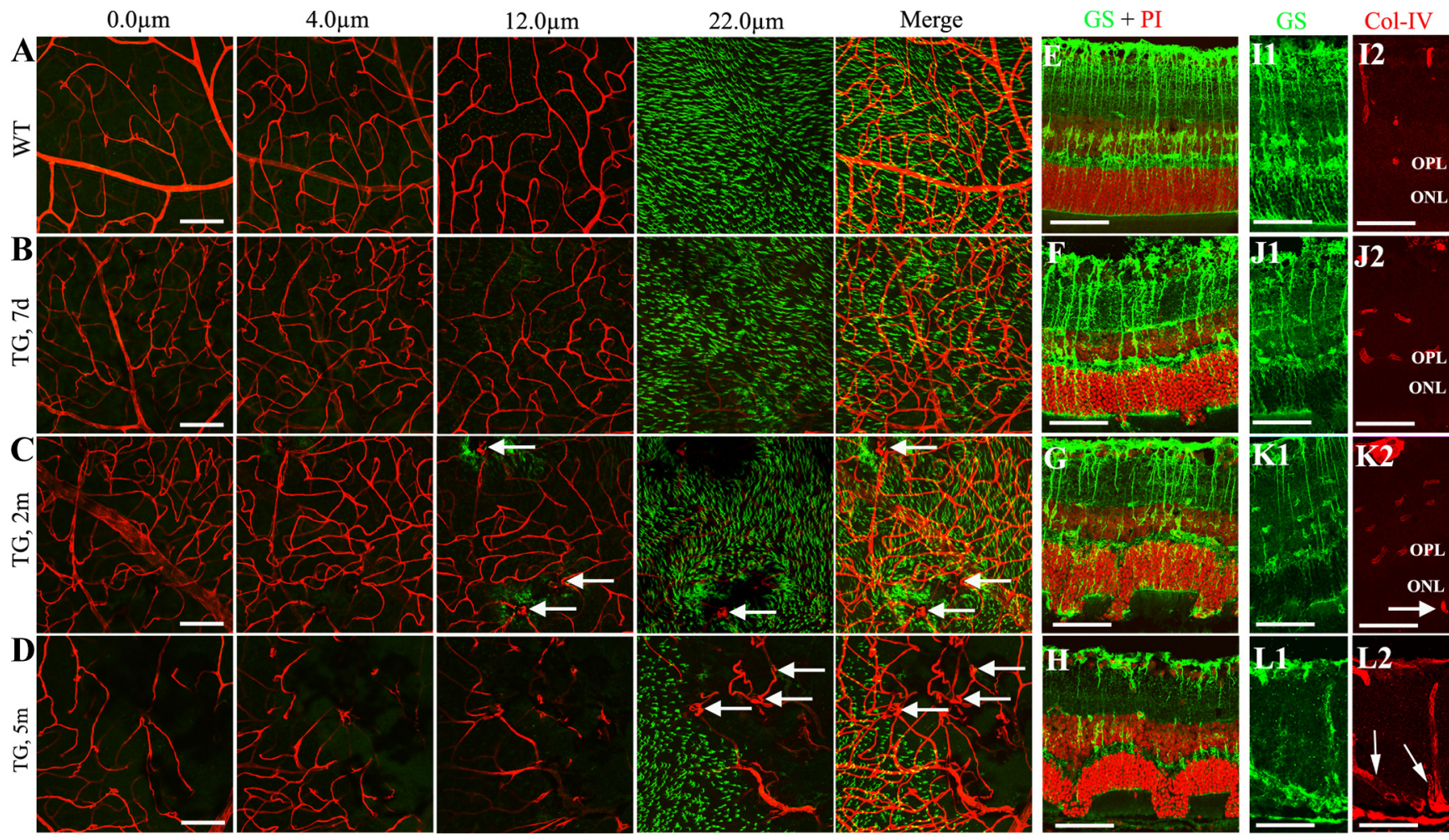

Figure 6. Mapping retinal vascular changes and photoreceptor injury with patchy loss of Müller cells. $A-D$, Retinal flat mounts were subject to double labeling using IB4, red for vessels and PNA for cone POS (green). Projected images were generated after scanning retinal flat mounts with the ganglion cell layer up at superficial ( $0 \mu \mathrm{m})$, intermediate $(4 \mu \mathrm{m})$, and deep vascular plexuses ( 12 $\mu \mathrm{m}$ ) and at the level of POS $(22 \mu \mathrm{m})$. $\boldsymbol{A}$, Wild-type (WT) mice showed smooth and well defined retinal vascular complexes, accompanied by regular and dense distribution of POS. $\boldsymbol{B}$, Seven days after TMX treatment, transgenic (TG) mice showed increased vascular tortuosity at all three levels and patchy loss of POS was visible. C, By 2 months, TG mice demonstrated increased vascular tortuosity and loss of POS and retinal capillaries. Budding new vessels (arrows) are detected in areas with photoreceptor damage. D, By 5 months, further loss of retinal capillaries and widespread abnormal vessels (arrows) were observed in areas with severe photoreceptor damage. $\boldsymbol{E}-\boldsymbol{H}$, Immunostaining for GS (green) and nuclear counterstaining using propidium iodide (PI, red) to correlate Müller cell loss with photoreceptor damage. I-L, Double immunostaining for GS (green, I1-L1) and collagen IV (Col-IV; red , I2-L2) to correlate Müller cell loss with the growth of deep retinal neovascularization (arrows in $\boldsymbol{K}$ and $\boldsymbol{L}$ ). Note new vessel growth from inner retina into deeper retina in $\boldsymbol{L}$ (arrows). Scale bars: $\boldsymbol{A}-\boldsymbol{D}, 100 \mu \mathrm{m} ; \boldsymbol{E}-\boldsymbol{L}, 50 \mu \mathrm{m}$.

retinal new vessels 2 months after Müller cell ablation was further confirmed by IHC for collagen IV (Fig. $5 L$, arrows).

\section{Mapping retinal vascular changes and photoreceptor damage with Müller cell loss}

Wild-type mice treated with TMX demonstrated smooth and well defined superficial, intermediate, and deep vascular networks overlying a regular and dense arrangement of POS (Fig. $6 A$ ). In transgenic mice, tortuous retinal vessels were observed at all three levels of the retinal vascular network and accompanied by patchy loss of POS $7 \mathrm{~d}$ after TMX treatment (Fig. 6B). After 2 months, loss of retinal capillaries was noted in regions of POS loss where growth of abnormal vessels was detected (Fig. 6C, arrows). By 5 months, pronounced loss of retinal capillaries and growth of abnormal vessels were commonly observed in transgenic mice (Fig. 6D, arrows). We performed double labeling to map Müller cell loss with photoreceptor damage and retinal vascular changes. Similar to what we observed in Figure 1, $Q$ and $R$, IHC on frozen sections showed that the extent of photoreceptor injury correlated well with the scale of Müller cell loss (Fig. $6 E-H$ ), and that the growth of deep retinal new vessels (Fig. 6 K2,L2, arrows) only occurred in areas of Müller cell ablation $>2$ months after TMXinduced Müller cell ablation (Fig. 6I-L).

\section{Changes in histology}

Disruption of retinal structure and development of deep retinal neovascularization were confirmed by light (Fig. 7A-D) and elec- tron microscopy (Fig. 7E). In eyes where neovascularization had developed, ultrastructural studies also revealed RPE clumping, proliferation, and migration into regions where new vessels occurred, but Bruch's membrane (BM) appeared intact (Fig. 7E), indicating that the new vessels originated from the inner retina rather than choroidal capillaries.

\section{Effects of intravitreal injection of CNTF on photoreceptor injury and BRB breakdown}

Since Müller cells are a significant source of neurotrophic factors (LaVail et al., 1992; Cayouette and Gravel, 1997; Walsh et al., 2001), we reasoned that Müller cell ablation would cause photoreceptor apoptosis as a result of the loss of support from trophic factors. We tested this hypothesis by performing intravitreal injection of recombinant CNTF. Intravitreal CNTF had no effect on wild-type retinas (Fig. $8 A, B$ ) but significantly reduced both the area of cone POS loss and the number of apoptotic cells in the ONL between 7 and $10 \mathrm{~d}$ after TMX treatment (Fig. 8C-F) in transgenic mice. We further examined whether CNTF treatment also inhibited BRB breakdown. Quantitative measurement of retinal permeability to FITCdextran and FA showed that CNTF treatment had no effect on BRB breakdown when administrated either soon after Müller cell ablation ( $4 \mathrm{~d}$ after TMX; Fig. 8G), or later after lesions of focal intense vascular leak had developed (4 months after TMX; Fig. $8 H$ ). 

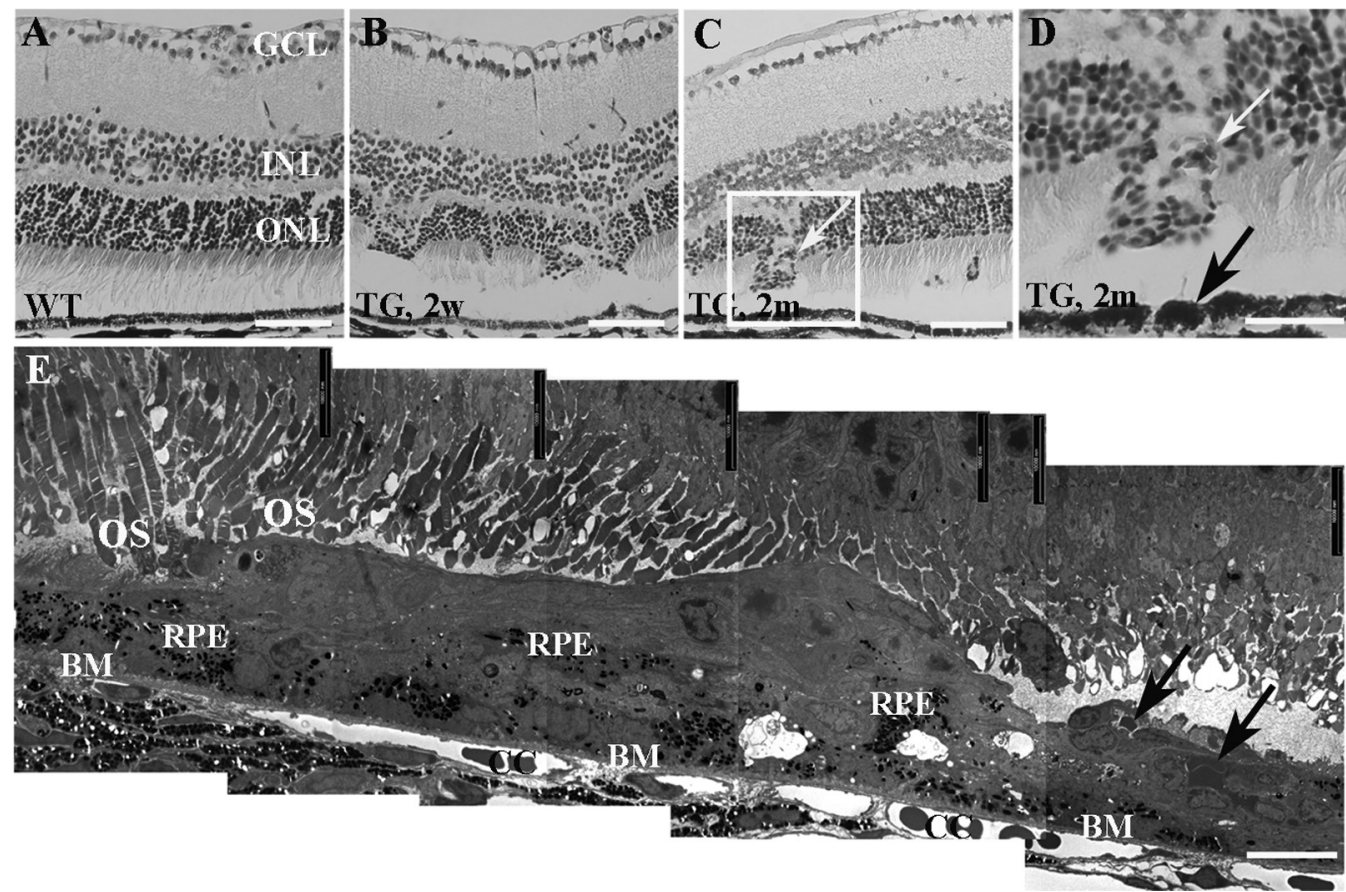

Figure 7. Retinal structural changes in histology. $A-D$, Light micrographs from wild-type (WT; $A)$ and transgenic $(T G ; B-D)$ retinas. Damage to photoreceptors was clearly visible but new vessels were not observed in TG mice 2 weeks $(\boldsymbol{B}$ ) while new vessels (white arrows, $\boldsymbol{C}$ and $\boldsymbol{D}$ ) appeared 2 months after TMX treatment in TG mice. $\boldsymbol{D}$, A higher power image of the squared area in $\boldsymbol{C}$. The black arrow in $\boldsymbol{D}$ points to clumping RPE in the disrupted area. $\boldsymbol{E}$, Electron microscopy revealed subretinal neovascularization (black arrows) but Bruch's membrane (BM) remained intact 3 months after TMX treatment. GCL, ganglion cell layer; INL, inner nuclear layer; $0 \mathrm{NL}$, outer nuclear layer; 0 S, photoreceptor outer segments; $C$, choroidal capillaries. Scale bars: $\boldsymbol{A}-\boldsymbol{C}, 50 \mu \mathrm{m} ; \boldsymbol{D}, 25 \mu \mathrm{m} ; \boldsymbol{E}, 10 \mu \mathrm{m}$.

\section{Imbalance between VEGF-A and PEDF expression after Müller cell ablation}

Since an imbalance between angiogenic and angiostatic factors is associated with BRB breakdown and retinal angiogenesis, we tested whether altered expression of VEGF-A and PEDF occurred after TMX-induced Müller cell ablation. Upregulation of VEGF-A was observed as early as $7 \mathrm{~d}$ after TMX treatment and persisted at 4 months, but significant reduction in PEDF expression was only detected 4 months after TMX when lesions of intense focal vascular leakage had developed (Fig. 9A,B). IHC showed persistent upregulation of VEGF-A around deep but not superficial retinal vessels 7 days and 4 months after TMX treatment (Fig. 9C), which was accompanied by reduction of PEDF expression in areas of Müller cell ablation (Fig. 9D). Double-label IHC indicated that the increased expression of VEGF-A around deep retinal vessels was more likely from pericytes than from vascular endothelial cells (Fig. 9E,F).

\section{Effects of intravitreal VEGFB20-4.1.1 on BRB breakdown and photoreceptor injury}

We next tested whether inhibition of VEGF-A activity reduced retinal vascular leakage. Intravitreal injection of VEGFB20-4.1.1, a novel VEGF antibody that binds both human and murine VEGF-A (Liang et al., 2006), inhibited BRB breakdown when the injection was performed $4 \mathrm{~d}$ after TMX treatment, and evaluations were conducted $6 \mathrm{~d}$ later (Fig. 10A). After injecting into eyes where intense focal retinal vascular leakage had developed, VEGFB20-4.1.1 dramatically inhibited the established vascular leakage when examined 3,7 , and $35 \mathrm{~d}$ after injection while lesions in eyes receiving vehicle remained relatively unchanged (Fig. $10 B, C)$. However, anti-VEGF-A treatment did not prevent photoreceptor loss in transgenic mice when VEGFB20-4.1.1 was injected $4 \mathrm{~d}$ after TMX treatment and the loss of POS was evaluated $6 \mathrm{~d}$ later (Fig. 10D,E).

\section{Discussion}

In this study, we have fully characterized changes in retinal neurons and vasculature after conditional Müller cell ablation in a novel transgenic model. We demonstrate that selective ablation of Müller cells led to neuronal damage on one hand, with photoreceptor apoptosis, and vasculopathy on the other, including telangiectasis, BRB breakdown, and intraretinal neovascularization. All of these features are found in many retinal diseases such as DR and MacTel-2. Our findings suggest that Müller glial dysfunction may provide a common link between photoreceptor injury and vascular pathology. The different responses of the neural and vascular changes to neuroprotective and anti-angiogenic treatments suggest that both may be required to treat the clinical consequences of Müller cell deficiency.

We have successfully produced a transgenic model for conditional Müller cell in the retina. $\beta$-gal activity was exclusively expressed in Müller cells in Rlbp1-LacZ mice, thus confirming that the regulatory region of the mouse Rlbp1 gene is sufficient to promote robust transgene expression in a Müller cell-specific manner (Vázquez-Chona et al., 2009). Müller cell-specific killing was supported by the predominant localization of apoptotic cells to the INL $1 \mathrm{~d}$ after TMX treatment in Rlbp1-DTA176 transgenic mice. Subsequent immunostaining for GS and SOX9 revealed that patchy loss of Müller cells occurred throughout the retina over time for 2 weeks. Müller cell ablation was further confirmed by electron microscopy showing decreased electron-dense end feet of the Müller glia in the ILM, loss of Müller cell bodies in the INL, and focal loss of the OLM. DTA is a cytotoxic protein that binds to a specific receptor on the cell surface and then is internalized by receptor-mediated endocytosis (Mitamura et al., 1995). DTA is translocated to the cytosol where it inactivates elongation factor 2 through ADP-ribosylation, thus inhibiting cellular protein synthesis and inducing cell death through apo- 

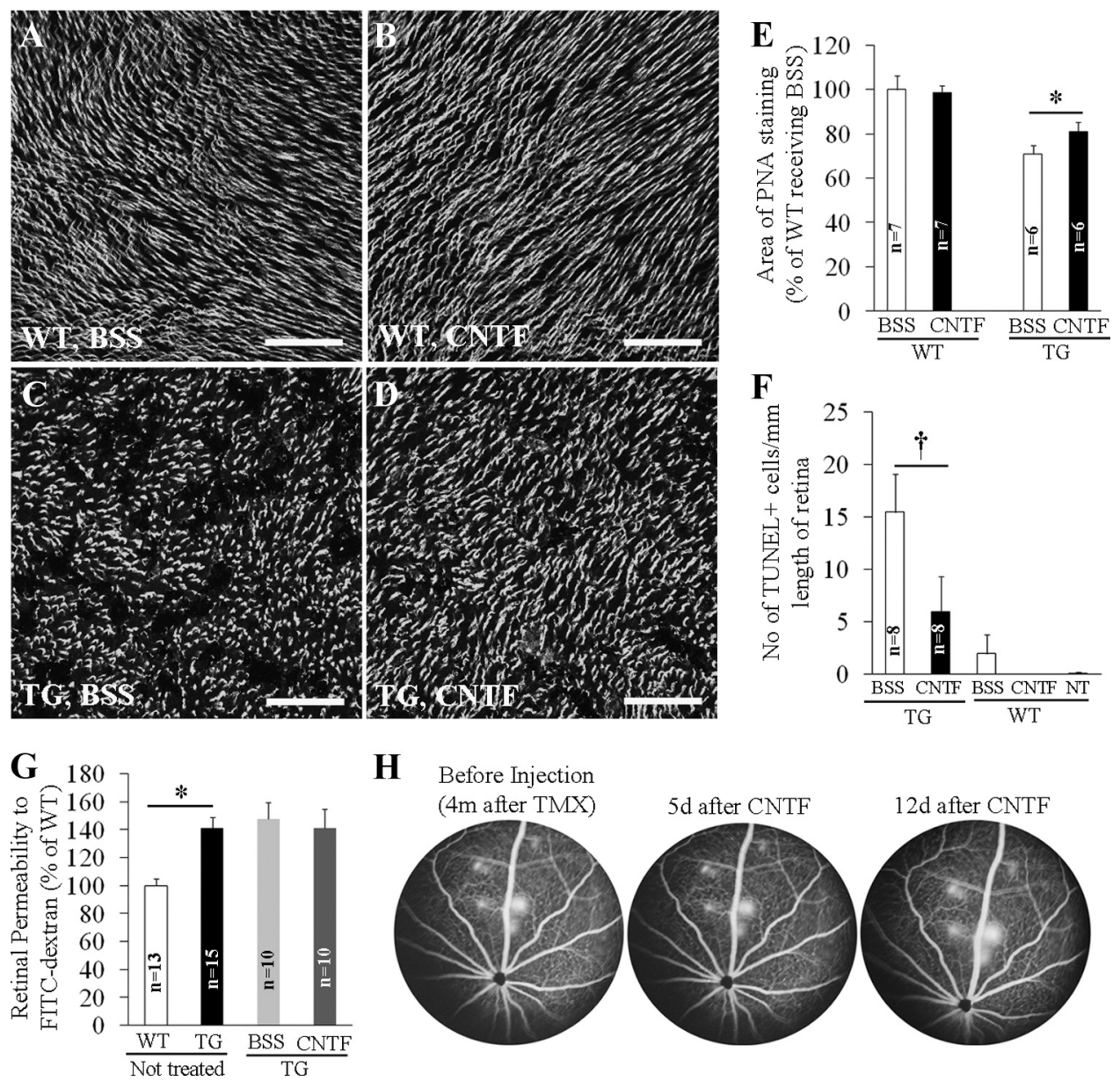

H Before Injection

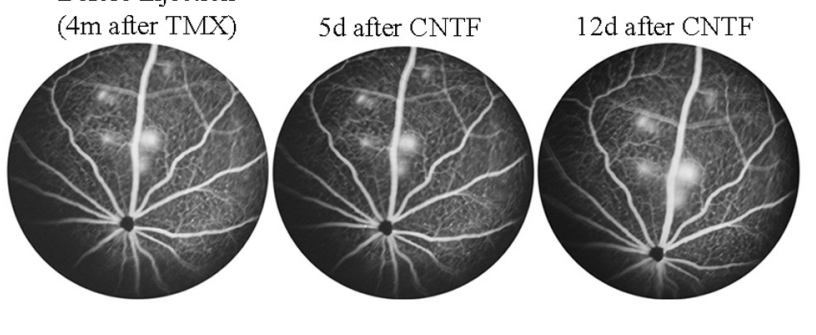

Figure 8. Effects of intravitreal injection of CNTF on photoreceptor injury $(\boldsymbol{A}-\boldsymbol{F})$ and BRB breakdown $(\boldsymbol{G}, \boldsymbol{H})$. $\boldsymbol{A}-\boldsymbol{D}$, CNTF $(0.5 \mu \mathrm{g})$ was injected $4 \mathrm{~d}$ after TMX treatment in one eye and the contralateral eye received BSS containing the same amount of BSA in each mouse. PNA staining was performed $6 \mathrm{~d}$ later. $E$, Quantitative analysis of PNA-stained retinal whole mounts. $p<0.01$, CNTF versus BSS in TG mice. $\boldsymbol{F}$, TUNEL for photoreceptor apoptosis. CNTF or BSS was injected $1 \mathrm{~d}$ after TMX treatment and TUNEL was performed $6 \mathrm{~d}$ after intravitreal injection. ${ }^{\dagger} p<0.05$, CNTF versus BSS. $\boldsymbol{G}$, Quantitative analysis of retinal permeability to fluorescence-labeled dextran. CNTF was injected $4 \mathrm{~d}$ after TMX treatment and permeability was measured $7 \mathrm{~d}$ later. ${ }^{*} p<0.01$, WT versus TG. $\boldsymbol{H}$, Effects of CNTF on established retinal vascular leakage. FA was performed to confirm the development of intense focal vascular leakage 4 months after Müller cell ablation and CNTF was injected 1 week later. Retinal vascular leakage was monitored by FA at 5 and $12 \mathrm{~d}$ after CNTF injection. Scale bars: $A-D, 100 \mu \mathrm{m}$.

ptosis (Morimoto and Bonavida, 1992; Mitamura et al., 1995; Ghosh et al., 2011). Because mouse cells have no receptor for DTA (Mitamura et al., 1995), leak or Cre-independent expression of DTA176 is unlikely to result in bystander cell lethality even if active DTA176 molecules are released from dead Müller cells in our transgenic mice (Maxwell et al., 1987; Wu et al., 2006). The negative findings in histology and TUNEL staining after intravitreal injection of retinal homogenates extracted from transgenic mice have further ruled out the bystander effect of DTA176 in this study.

The dynamics of photoreceptor damage is consistent with that of Müller cell loss between 7 and $28 \mathrm{~d}$ after TMX induction. Damage to photoreceptors was demonstrated by protrusion of the ONL into the subretinal space and loss of cone POS. The former is likely due to focal loss of the OLM, which is the outer end feet of Müller glia. Photoreceptor damage was also supported by ERG, as indicated by suppression of the a- and b-wave responses of both rods and cones in transgenic mice. These observations are consistent with previous reports that Müller cell disruption leads to retinal dysplasia and degeneration during postnatal development (Rich et al., 1995; Dubois-Dauphin et al., 2000; Dyer and Cepko, 2000). Because Müller cells play a central role in retinal glucose metabolism and in the protection of neu- rons through the uptake and degradation of glutamate, release of neurotrophic factors, and secretion of the antioxidants, it is likely that disruption of these important functions by selective ablation of Müller cells results in neuronal damage. Overall, our findings on photoreceptor damage after Müller cell ablation reflect the importance of Müller cells in the maintenance of photoreceptor health and function. The fact that ganglion cells and neurons in the inner retina were much less affected in our model, at least based on histologic and ultrastructural analysis, suggests that they may receive support from other retinal glia such as astrocytes and, potentially, activated microglia (Oliet et al., 2001; Karlstetter et al., 2010). This warrants further investigation.

In the mature retina, Müller glia are the major source of CNTF, which is among the most potent of trophic factors protecting retinal neurons (LaVail et al., 1992; Cayouette and Gravel, 1997; Walsh et al., 2001; Rhee et al., 2007). Loss of neurotrophic support from Müller cells would affect the survival of neurons. Our data suggest that photoreceptors can be rescued by supplement of CNTF in conditions linked to Müller cell loss or deficiency. CNTF treatment significantly reduced both the area of POS loss and the number of photoreceptors undergoing apoptosis, thus indicating that the photoreceptor injury is associated with the loss of neuroprotective factors normally produced by Müller cells. 
A
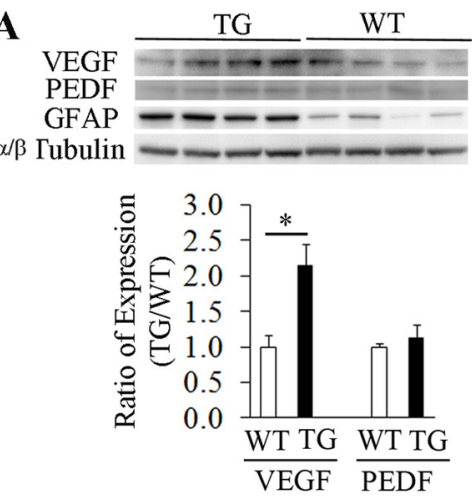

B
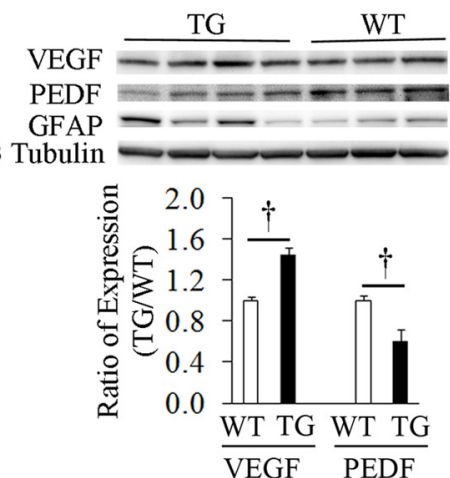
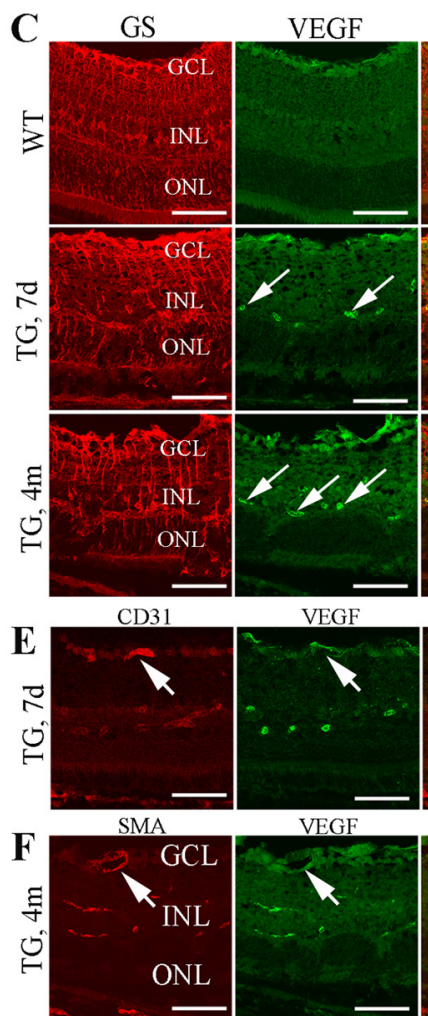

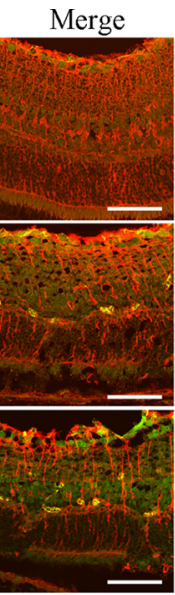

Merge
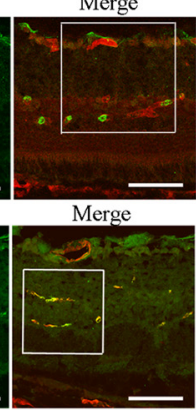

D PEDF

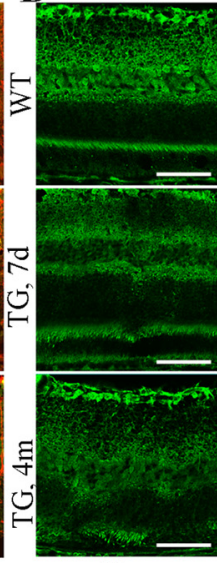

Merge

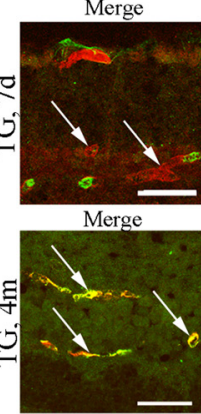

Figure 9. Imbalanced expression of VEGF-A and PEDF after Müller cell ablation. $\boldsymbol{A}$, Western blot showed upregulation of VEGF-A while the expression of PEDF remained relatively unchanged $7 \mathrm{~d}$ after Müller cell ablation. ${ }^{*} p<0.01$, TG versus WT, $n=8$ in each group. $\boldsymbol{B}$, By 4 months after Müller cell ablation, Western blot revealed significant upregulation of VEGF-A and downregulation of PEDF. ${ }^{\dagger} p<0.05$, TG versus WT controls, $n=7-8$ in each group. TG mice showed persistent upregulation of GFAP 7 days and 4 months after Müller cell ablation, indicating that the survival Müller cells were at a stage of reactive gliosis. C, Double-label IHC revealed that VEGF-A was weakly expressed in the superficial retina in WT but strong immunoreactivity was detected around deep retinal vessels (arrows) in TG retinas $7 \mathrm{~d}$ and 4 months after Müller cell ablation. $\boldsymbol{D}$, Reduced expression of PEDF in areas of Müller cell ablation. $\boldsymbol{E}, \boldsymbol{F}$, Double-label IHC using CD31 for the vascular endothelium and SMA for pericytes in combination and antibody to VEGF-A suggested that overexpression of VEGF-A was more likely from pericytes ( $\boldsymbol{F}$, small arrows) than from the vascular endothelium ( $\boldsymbol{E}$, small arrows). Note: the superficial retinal vessels did not overexpress VEGF-A (large arrows in $\boldsymbol{E}$ and $\boldsymbol{F}$ ). GS, glutamine synthetase; GCL, ganglion cell layer; INL, inner nuclear layer; ONL, outer nuclear layer. Scale bars: $\boldsymbol{C}-\boldsymbol{F}, 50 \mu \mathrm{m}$; the squared area in $\boldsymbol{E}, 30 \mu \mathrm{m}$; the squared area in $\boldsymbol{F}, 20 \mu \mathrm{m}$.

Breakdown of the BRB occurred rapidly after selective Müller cell ablation, suggesting that Müller cell loss may directly disrupt the anatomical structure of the retinal vessels, which they closely invest (Bringmann et al., 2006; Erickson et al., 2007). This was supported by our finding that the tight junction protein claudin-5 was reduced in regions where vascular tufts were forming. Previously we found similar changes in the BRB and claudin-5 expression after disrupting Müller glia by subretinal injection of DL- $\alpha$-aminoadipic acid, a reportedly glia-specific toxin in rats (Shen et al., 2010). A link between glial disruption, reduced expression of junction-associated proteins, and bloodbrain barrier breakdown has also been previously found in the brain (Willis et al., 2004, 2007). Upregulation of VEGF-A expression was observed as early as $7 \mathrm{~d}$ after TMX induction and it persisted for at least 4 months in our transgenic mice. Overexpression of VERGF-A was predominantly around deep retinal vessels in the region of Müller cell ablation. Double-label IHC indicated that the increased expression of VEGF-A was most likely from pericytes rather than the vascular endothelium. Overall, our observations also reflect the importance of Müller cells in the formation and maintenance of a healthy microenvironment for BRB function.

Overexpression of VEGF-A has been closely linked to ocular angiogenesis such as DR, age-related macular degeneration, and MacTel-2 (Matsuoka et al., 2004; Jorge et al., 2007; Kovach and Rosenfeld, 2009; Mohan et al., 2012). We found that deep retinal neovascularization mostly occurred from 2 months after TMX- induced Müller cell ablation. By 4 months after TMX treatment when the majority of eyes developed deep retinal new vessels, Müller cell ablation resulted in both upregulation of VEGF-A and reduced expression of $\mathrm{PEDF}$, thus altering the balance between angiogenic and angiostatic factor in regions with Müller cell loss. Our results support the hypothesis that selective Müller cell ablation induces long-term deregulations of VEGF and PEDF expression, thus contributing to the growth of deep retinal neovascularization.

We next tested whether anti-VEGF-A therapy is effective in inhibition of BRB breakdown induced by selective Müller cell ablation. Our results showed that intravitreal injection of VEGFB20-4.1.1 attenuated the retinal vascular permeability when the VEGF antibody was injected $4 \mathrm{~d}$ after TMX induction and analysis was conducted 6 d later. Furthermore, anti-VEGF-A therapy was also effective at 4 months after TMX treatment when deep retinal neovascularization had developed. The inhibitory effect of anti-VEGF-A therapy on BRB breakdown further confirms that VEGF-A overexpression plays an important role in retinal vascular pathology caused by Müller cell loss.

Interestingly, in contrast to its protective effect on photoreceptors, CNTF treatment had no effect on BRB breakdown when injected either early ( $4 \mathrm{~d}$ after TMX treatment) or later ( 4 months after TMX treatment) when lesions of focal intense leakage had occurred. Similarly, VEGFB20-4.1.1 inhibited BRB breakdown but had no effect on photoreceptor injury. These results suggest that photoreceptor damage and retinal vascular pathology may 
A

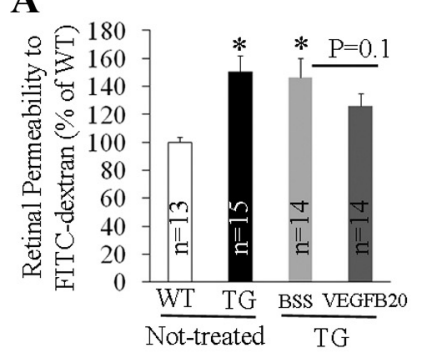

C

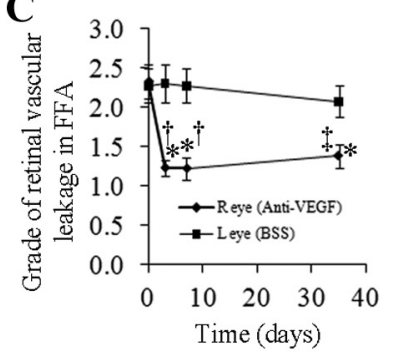

B
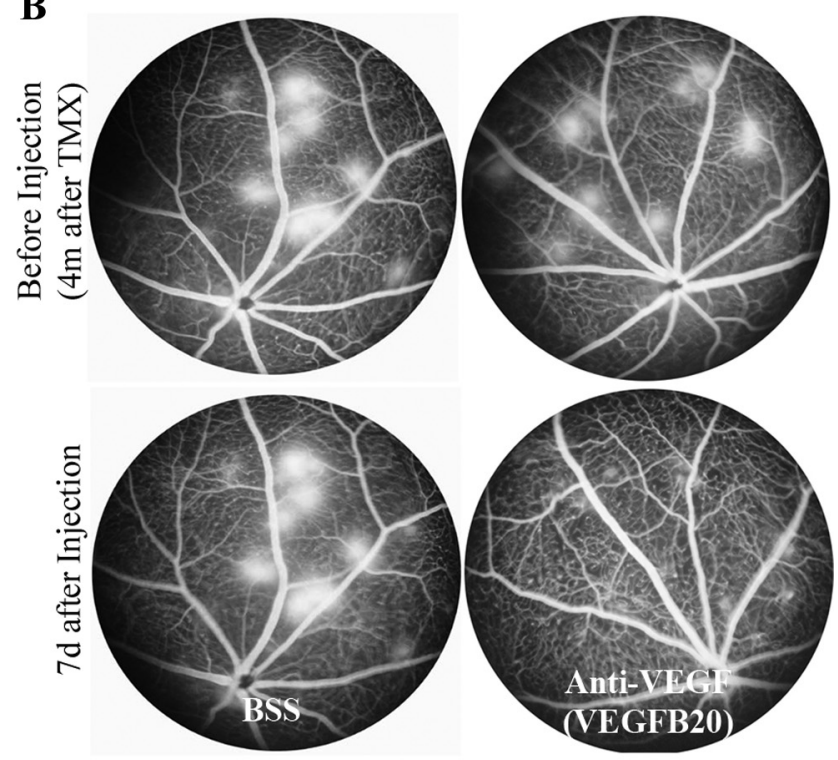
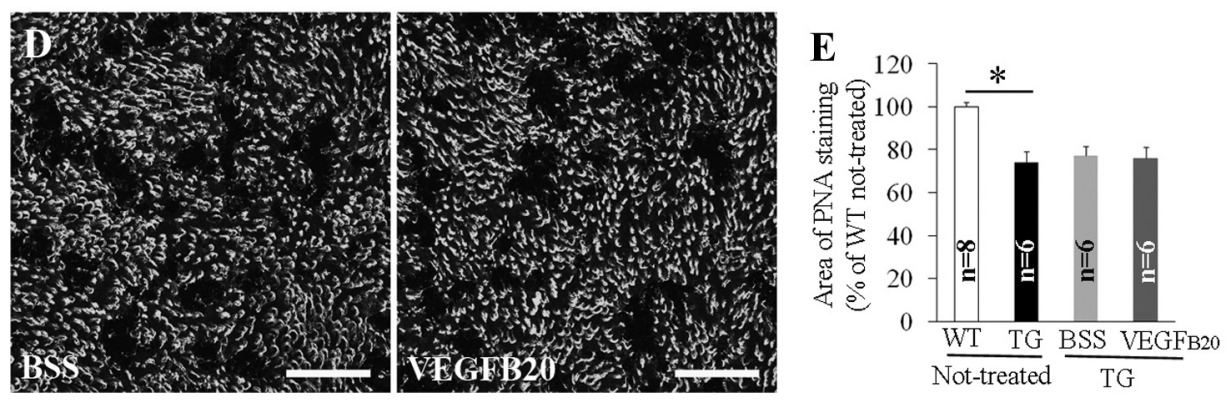

Figure 10. Effects of anti-VEGF-A therapy with VEGFB20-4.1.1 on BRB breakdown $(\boldsymbol{A}-\boldsymbol{C})$ and photoreceptor injury $(\boldsymbol{D}, \boldsymbol{E})$. VEGFB20-4.1.1 (16.38 $\mu \mathrm{g})$ was injected in one eye and the contralateral eye received BSS containing the same amount of BSA in each mouse. $A$, Quantitative measurement of retinal permeability to fluorescence-labeled dextran. VEGFB20-4.1.1 was injected $4 \mathrm{~d}$ after TMX treatment and retinal permeability was measured 6 d later. ${ }^{*} p<0.01 ;{ }^{\dagger} p<0.05$, both TG versus WT. B, FA was performed to confirm the development of intense focal vascular leakage 4 months after Müller cell ablation and VEGFB20-4.1.1 was injected 1 week later. Retinal vascular leakage was monitored by FA at various time points after intravitreal injection. $C$, Graded fluorescein leakage 3,7 , and 35 d after injection of VEGFB20-4.1.1 or BSS using scales as described in Figure $4 .{ }^{*} p<0.01$, versus before injection at day 0 ; ${ }^{\dagger} p<0.01$ and ${ }^{\ddagger} p<0.05$, anti-VEGF-A (VEGFB20-4.1.1) versus $B S S$, respectively; $n=18$ at each time point. $\boldsymbol{D}, \boldsymbol{E}$, Analysis of PNA staining of retinal whole mounts showed anti-VEGF-A action had no effect on protecting photoreceptor injury $\left({ }^{*} p<0.01\right.$, WT versus TG). Scale bars: $D, 100 \mu \mathrm{m}$.

be independent events that are caused by Müller cell loss but are otherwise unrelated.

Results from this study may improve our understanding of the potential impacts of Müller cell dysfunction on retinal neurons and vasculature in DR. It has been well established that diabetes induces apoptosis of a variety of retinal cells including endothelial cells, pericytes, neurons, and Müller cells (Hammes et al., 1995; Barber et al., 2011; Wu et al., 2012). However, the relationships between apoptosis of different classes of retinal cells and vascular complications remain unclear. In the diabetic retina, Müller cells actually display both apoptosis and reactive gliosis, but the rate of Müller glial activation appears to exceed that of apoptosis (Bringmann et al., 2006, 2009; Barber et al., 2011). Our data indicate that patchy loss of Müller cells is sufficient to induce photoreceptor damage, BRB breakdown and intraretinal neovascularization. It is plausible that over many years of diabetes, progressive dysfunction of retinal Müller cells may affect glutamate metabolism, reduce production of trophic factors that are important for the survival of both retinal neurons and vascular cells, and disturb the balance between angiogenic and angiostatic factors, thus contributing to neuronal and vascular complications in DR.
The photoreceptor damage and retinal vasculopathy in the transgenic model are similar to features of MacTel-2 in humans. Optical coherence tomography has recently demonstrated a neurodegenerative process in MacTel-2, with photoreceptor damage mapped to loss of vision (Charbel Issa et al., 2010). Vascular changes in MacTel-2 are characterized vascular telangiectasis, leak, and deep retinal neovascularization (Gass and Blodi, 1993; Yannuzzi et al., 2006). A recent study showed prominent loss of Müller cell markers in the central retina after analysis of histological changes in a donor eye from a MacTel-2 patient (Powner et al., 2010); this finding has been confirmed in the second donor of MacTel-2 (M. Futtiger, unpublished data). In light of the fact that a cone-shaped zone of Müller cells acts as a critical structural and functional support for the fovea (Gass, 1999), our observations from the transgenic model strongly support the hypothesis that Müller cell dysfunction is a major player in the pathogenesis of MacTel-2.

In summary, we have shown that selective Müller cell ablation is sufficient to induce photoreceptor degeneration, vascular telangiectasis, BRB breakdown, and intraretinal neovascularization, which are major features shared by a number of retinal diseases such as DR and MacTel-2. Our findings indicate that Müller glial 
deficiency may have a so far unappreciated role and be a mechanistic link between neuronal and vascular pathology in retinal diseases. This is the first study to describe that Müller glial deficiency may be one of the upstream causes of retinal neural and vascular pathologies in retinal diseases. A sustained-release formulation of CNTF using encapsulated cell technology has shown encouraging results in protecting photoreceptors in humans with retinal pigmentosa and age-related macular degeneration (Sieving et al., 2006; Zhang et al., 2011). Anti-VEGF-A therapy has been widely used to treat retinal vascular diseases. The clinical implication of our findings is that a combined therapeutic approach that targets the neuropathy as well as the vasculopathy may be required to treat diseases caused by dysfunction of Müller cells and, potentially, other glial cells in the CNS.

\section{References}

Abukawa H, Tomi M, Kiyokawa J, Hori S, Kondo T, Terasaki T, Hosoya K (2009) Modulation of retinal capillary endothelial cells by Müller glial cell-derived factors. Mol Vis 15:451-457.

Ali TK, Al-Gayyar MM, Matragoon S, Pillai BA, Abdelsaid MA, Nussbaum JJ, El-Remessy AB (2011) Diabetes-induced peroxynitrite impairs the balance of pro-nerve growth factor and nerve growth factor, and causes neurovascular injury. Diabetologia 54:657-668.

Barber AJ, Antonetti DA, Gardner TW (2000) Altered expression of retinal occludin and glial fibrillary acidic protein in experimental diabetes. The Penn State Retina Research Group. Invest Ophthalmol Vis Sci 41:35613568.

Barber AJ, Gardner TW, Abcouwer SF (2011) The significance of vascular and neural apoptosis to the pathology of diabetic retinopathy. Invest Ophthalmol Vis Sci 52:1156-1163.

Bringmann A, Pannicke T, Grosche J, Francke M, Wiedemann P, Skatchkov SN, Osborne NN, Reichenbach A (2006) Müller cells in the healthy and diseased retina. Prog Retin Eye Res 25:397-424.

Bringmann A, Iandiev I, Pannicke T, Wurm A, Hollborn M, Wiedemann P, Osborne NN, Reichenbach A (2009) Cellular signaling and factors involved in Müller cell gliosis: neuroprotective and detrimental effects. Prog Retin Eye Res 28:423-451.

Bui BV, Armitage JA, Vingrys AJ (2002) Extraction and modelling of oscillatory potentials. Doc Ophthalmol 104:17-36.

Cayouette M, Gravel C (1997) Adenovirus-mediated gene transfer of ciliary neurotrophic factor can prevent photoreceptor degeneration in the retinal degeneration (rd) mouse. Hum Gene Ther 8:423-430.

Charbel Issa P, Troeger E, Finger R, Holz FG, Wilke R, Scholl HP (2010) Structure-function correlation of the human central retina. PLoS One 5:e12864.

Dubois-Dauphin M, Poitry-Yamate C, de Bilbao F, Julliard AK, Jourdan F, Donati G (2000) Early postnatal Müller cell death leads to retinal but not optic nerve degeneration in NSE-Hu-Bcl-2 transgenic mice. Neuroscience 95:9-21.

Dyer MA, Cepko CL (2000) Control of Müller glial cell proliferation and activation following retinal injury. Nat Neurosci 3:873-880.

Erickson KK, Sundstrom JM, Antonetti DA (2007) Vascular permeability in ocular disease and the role of tight junctions. Angiogenesis 10:103-117.

Fletcher EL, Phipps JA, Ward MM, Puthussery T, Wilkinson-Berka JL (2007) Neuronal and glial cell abnormality as predictors of progression of diabetic retinopathy. Curr Pharm Des 13:2699-2712.

Gass JD (1999) Müller cell cone, an overlooked part of the anatomy of the fovea centralis: hypotheses concerning its role in the pathogenesis of macular hole and foveomacualr retinoschisis. Arch Ophthalmol 117:821823.

Gass JD, Blodi BA (1993) Idiopathic juxtafoveolar retinal telangiectasis. Update of classification and follow-up study. Ophthalmology 100:15361546.

Ghosh A, Manrique-Hoyos N, Voigt A, Schulz JB, Kreutzfeldt M, Merkler D, Simons M (2011) Targeted ablation of oligodendrocytes triggers axonal damage. PLoS One 6:e22735.

Guidolin D, Vacca A, Nussdorfer GG, Ribatti D (2004) A new image analysis method based on topological and fractal parameters to evaluate the angiostatic activity of docetaxel by using the Matrigel assay in vitro. Microvasc Res 67:117-124.
Hammes HP, Federoff HJ, Brownlee M (1995) Nerve growth factor prevents both neuroretinal programmed cell death and capillary pathology in experimental diabetes. Mol Med 1:527-534.

Jorge R, Costa RA, Calucci D, Scott IU (2007) Intravitreal bevacizumab (Avastin) associated with the regression of subretinal neovascularization in idiopathic juxtafoveolar retinal telangiectasis. Graefe's Arch Clin Exp OPhthalmol 245:1045-1048.

Karlstetter M, Ebert S, Langmann T (2010) Microglia in the healthy and degenerating retina: insights from novel mouse models. Immunobiology 215:685-691.

Kovach JL, Rosenfeld PJ (2009) Bevacizumab (avastin) therapy for idiopathic macular telangiectasia type II. Retina 29:27-32.

LaVail MM, Unoki K, Yasumura D, Matthes MT, Yancopoulos GD, Steinberg RH (1992) Multiple growth factors, cytokines, and neurotrophins rescue photoreceptors from the damaging effects of constant light. Proc Natl Acad Sci U S A 89:11249-11253.

Liang WC, Wu X, Peale FV, Lee CV, Meng YG, Gutierrez J, Fu L, Malik AK, Gerber HP, Ferrara N, Fuh G (2006) Cross-species vascular endothelial growth factor (VEGF)-blocking antibodies completely inhibit the growth of human tumor xenografts and measure the contribution of stromal VEGF. J Biol Chem 281:951-961.

Matsuoka M, Ogata N, Otsuji T, Nishimura T, Takahashi K, Matsumura M (2004) Expression of pigment epithelium derived factor and vascular endothelial growth factor in choroidal neovascular membranes and polypoidal choroidal vasculopathy. Br J Ophthalmol 88:809-815.

Maxwell F, Maxwell IH, Glode LM (1987) Cloning, sequence determination, and expression in transfected cells of the coding sequence for the tox 176 attenuated diphtheria toxin A chain. Mol Cell Biol 7:1576-1579.

Mitamura T, Higashiyama S, Taniguchi N, Klagsbrun M, Mekada E (1995) Diphtheria toxin binds to the epidermal growth factor (EGF)-like domain of human heparin-binding EGF-like growth factor/diphtheria toxin receptor and inhibits specifically its mitogenic activity. J Biol Chem 270: 1015-1019.

Miyahara S, Kiryu J, Yamashiro K, Miyamoto K, Hirose F, Tamura H, Katsuta H, Nishijima K, Tsujikawa A, Honda Y (2004) Simvastatin inhibits leukocyte accumulation and vascular permeability in the retinas of rats with streptozotocin-induced diabetes. Am J Pathol 164:1697-1706.

Mohan N, Monickaraj F, Balasubramanyam M, Rema M, Mohan V (2012) Imbalanced levels of angiogenic and angiostatic factors in vitreous, plasma and postmortem retinal tissue of patients with proliferative diabetic retinopathy. J Diabetes Complications.

Morimoto H, Bonavida B (1992) Diphtheria toxin- and Pseudomonas A toxin-mediated apoptosis. ADP ribosylation of elongation factor-2 is required for DNA fragmentation and cell lysis and synergy with tumor necrosis factor-alpha. J Immunol 149:2089-2094.

Moxon-Lester L, Takamoto K, Colditz PB, Barnett NL (2009) S-adenosylL-methionine restores photoreceptor function following acute retinal ischemia. Visual neuroscience 26:429-441.

Oliet SH, Piet R, Poulain DA (2001) Control of glutamate clearance and synaptic efficacy by glial coverage of neurons. Science 292:923-926.

Ooto S, Hangai M, Takayama K, Arakawa N, Tsujikawa A, Koizumi H, Oshima S, Yoshimura N (2011) High-resolution photoreceptor imaging in idiopathic macular telangiectasia type 2 using adaptive optics scanning laser ophthalmoscopy. Invest Ophthalmol Vis Sci 52:5541-5550.

Powner MB, Gillies MC, Tretiach M, Scott A, Guymer RH, Hageman GS, Fruttiger M (2010) Perifoveal Müller cell depletion in a case of macular telangiectasia type 2. Ophthalmology 117:2407-2416.

Rhee KD, Ruiz A, Duncan JL, Hauswirth WW, Lavail MM, Bok D, Yang XJ (2007) Molecular and cellular alterations induced by sustained expression of ciliary neurotrophic factor in a mouse model of retinitis pigmentosa. Invest Ophthalmol Vis Sci 48:1389-1400.

Rich KA, Figueroa SL, Zhan Y, Blanks JC (1995) Effects of Müller cell disruption on mouse photoreceptor cell development. Exp Eye Res 61:235248.

Sallo FB, Leung I, Chung M, Wolf-Schnurrbusch UE, Dubra A, Williams DR, Clemons T, Pauleikhoff D, Bird AC, Peto T (2011) Retinal crystals in type 2 idiopathic macular telangiectasia. Ophthalmology 118:2461-2467.

Shen WY, Lai CM, Graham CE, Binz N, Lai YK, Eade J, Guidolin D, Ribatti D, Dunlop SA, Rakoczy PE (2006) Long-term global retinal microvascular changes in a transgenic vascular endothelial growth factor mouse model. Diabetologia 49:1690-1701. 
Shen W, Li S, Chung SH, Gillies MC (2010) Retinal vascular changes after glial disruption in rats. J Neurosci Res 88:1485-1499.

Sieving PA, Caruso RC, Tao W, Coleman HR, Thompson DJ, Fullmer KR, Bush RA (2006) Ciliary neurotrophic factor (CNTF) for human retinal degeneration: phase I trial of CNTF delivered by encapsulated cell intraocular implants. Proc Natl Acad Sci U S A 103:3896-3901.

Vázquez-Chona FR, Clark AM, Levine EM (2009) Rlbp1 promoter drives robust Müller glial GFP expression in transgenic mice. Invest Ophthalmol Vis Sci 50:3996-4003.

Walsh N, Valter K, Stone J (2001) Cellular and subcellular patterns of expression of bFGF and CNTF in the normal and light stressed adult rat retina. Exp Eye Res 72:495-501.

Willis CL, Nolan CC, Reith SN, Lister T, Prior MJ, Guerin CJ, Mavroudis G, Ray DE (2004) Focal astrocyte loss is followed by microvascular damage, with subsequent repair of the blood-brain barrier in the apparent absence of direct astrocytic contact. Glia 45:325-337.

Willis CL, Taylor GL, Ray DE (2007) Microvascular P-glycoprotein expression at the blood-brain barrier following focal astrocyte loss and at the fenestrated vasculature of the area postrema. Brain Res 1173:126-136.

Wu M, Yang S, Elliott MH, Fu D, Wilson K, Zhang J, Du M, Chen J, Lyons T (2012) Oxidative and Endoplasmic Reticulum Stresses Mediate Apoptosis Induced by Modified LDL in Human Retinal Müller Cells. Invest Ophthalmol Vis Sci 53:4595-4604.

Wu S, Wu Y, Capecchi MR (2006) Motoneurons and oligodendrocytes are sequentially generated from neural stem cells but do not appear to share common lineage-restricted progenitors in vivo. Development 133:581590.

Yannuzzi LA, Bardal AM, Freund KB, Chen KJ, Eandi CM, Blodi B (2006) Idiopathic macular telangiectasia. Arch Ophthalmol 124:450-460.

Zhang K, Hopkins JJ, Heier JS, Birch DG, Halperin LS, Albini TA, Brown DM, Jaffe GJ, Tao W, Williams GA (2011) Ciliary neurotrophic factor delivered by encapsulated cell intraocular implants for treatment of geographic atrophy in age-related macular degeneration. Proc Natl Acad Sci U S A 108:6241-6245. 